\title{
Nursing staff dynamics and implications for maternal health provision in public health facilities in the context of HIV/AIDS
}

Loveday Penn-Kekana

Duane Blaauw

Khin San Tint

Desiree Monareng

Jane Chege

Population Council

Follow this and additional works at: https://knowledgecommons.popcouncil.org/departments_sbsr-rh

Part of the Demography, Population, and Ecology Commons, International Public Health Commons, Maternal and Child Health Commons, Public Health Education and Promotion Commons, and the Women's Health Commons

How does access to this work benefit you? Let us know!

\section{Recommended Citation}

Penn-Kekana, Loveday, Duane Blaauw, Khin San Tint, Desiree Monareng, and Jane Chege. 2005. "Nursing staff dynamics and implications for maternal health provision in public health facilities in the context of HIV/AIDS," FRONTIERS Final Report. Washington, DC: Population Council. 


\title{
Nursing Staff Dynamics and Implications \\ for Maternal Health Provision \\ in Public Health Facilities in the Context of HIV/AIDS
}

\author{
Loveday Penn-Kekana, \\ Duane Blaauw, \\ Khin San Tint, \\ Desiree Monareng \\ Centre for Health Policy, School of Public Health \\ University of the Witwatersrand \\ Jane Chege \\ Frontiers in Reproductive Health \\ Population Council
}

August 2005

This study was funded by the US AGENCY FOR INTERNATIONAL

DEVELOPMENT (USAID) under the terms of the Frontiers in Reproductive Health Cooperative Agreement Number HRN-A-00-98-00012-00 and Population Council subaward number A104.13A. The opinions expressed herein are those of the authors and do not necessarily reflect the views of USAID. 


\section{SUMMARY}

This study aimed to document nursing staff dynamics in maternal health services, and to explore the factors associated with these dynamics. We have used the term nursing staffing dynamics to encompass a range of human resource processes including staff turnover, absenteeism, average length of stay in a facility, vacancy rates and workload. The study was carried out in Limpopo, KwaZulu-Natal and Mpumalanga provinces in South Africa. A fax questionnaire was sent out to all public sector hospitals providing maternity services in the three provinces. Site visits were made to 15 hospitals and 27 clinics, which were selected using multi-stage cluster approach sampling.

The study had four components:

- Measurement of nursing staff dynamics

- A motivational survey

- A discrete choice experiment

- Qualitative analysis of open-ended questions

Ethical clearance was obtained from the Human Research Ethics Committee at the University of the Witwatersrand.

Overall, hospitals and clinics had a vacancy rate of $22.6 \%$ and $26.5 \%$ respectively, with clinics in Mpumalanga having the highest vacancy rates. Most (83\%) hospitals but only $11.1 \%$ of clinics had advanced midwives and $42 \%$ of facilities reported that they had lost an advanced midwife during the last year. The average length of service of sisters-in-charge was more than five years; mean number of years that professional nurses ${ }^{1}$ had worked at the facility was nine in Mpumalanga and KwaZulu-Natal and nearly six years in Limpopo. In the sampled clinics the mean workload was 770 clients per month per professional nurse. The mean number of deliveries per professional nurse per month in hospitals was 16.5. The results suggest that although nursing staff turnover, shortages of staff and workload are extremely problematic at some facilities, not all facilities are equally affected. In terms of absenteeism it was found that although a large number of days were taken off sick, these were often isolated days, and not long periods of sick leave.

A high percentage of nursing staff working in public facilities were demotivated, burnt out, and were considering leaving the facility where they were working. A range of factors, both financial and non-financial, were associated with nurses considering going overseas. Inadequate pay, poor promotion, feeling unsupported by management and having bad relationships at work were all associated with lack of organisational commitment.

1 Professional nurses, who are also known as registered nurses, have completed a four-year training course at a nursing college or university. Since 1985 midwifery has been integrated into this four-year basic training. 
Nurses with children under the age of 18, and in the middle age group of $30-49$ years were more likely to be considering going overseas than younger or older nurses. Wanting a better future for their children, and needing money to pay school and university fees, were mentioned as being a key motivation for nurses going overseas. The HIV/AIDS epidemic was found to have a role, but not to be driving problems with nursing morale in maternity units.

The Discrete Choice Experiment showed that financial and non-financial factors influenced nurses' decisions on where to work. Good management, and a wellequipped hospital were as influential over nurses' choices as a $15 \%$ pay increase. The qualitative data showed that various policy initiatives instigated by the government to retain staff, such as the rural allowance, have had mixed outcomes.

As a result of high numbers of nurses feeling demoralised, there is not a conducive environment for policy interventions. Policy makers need to pay more attention to how policies are implemented and the impact of policies on the relationships between nurses, and nurses and managers in facilities. It is recommended that improving facility management should be a priority of the National Department, but this is challenging as many facility managers themselves are demoralised.

This report is an abridged account of the methodology and results. Please contact Loveday Penn-Kekana at loveday.penn-kekana@nhls.ac.za if you would like more detailed information about the research methodology used or the results of the study. 


\section{CONTENTS}

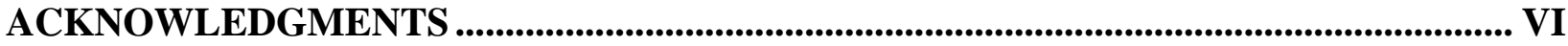

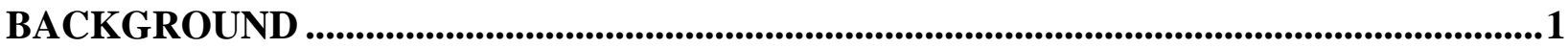

STATEMENT OF THE PROBLEM .................................................................................................3

Poor Maternal Health Outcomes in South Africa ..........................................................

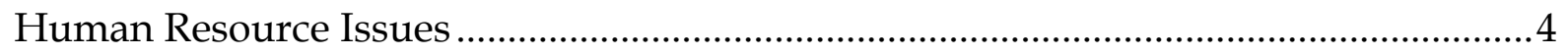

The Impact of HIV / AIDS ............................................................................................ 5

Maternal Health Services as a Probe to Understand Reproductive Health

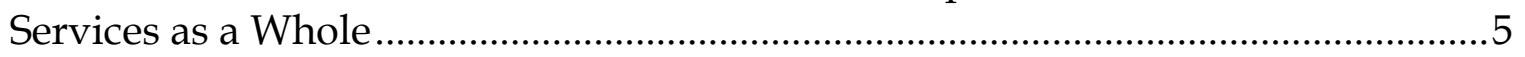

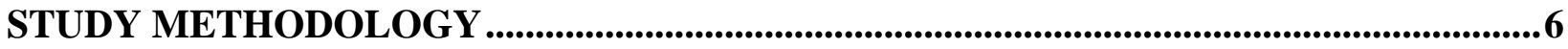

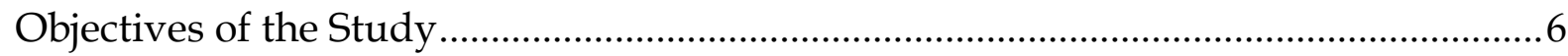

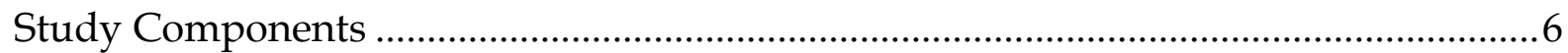

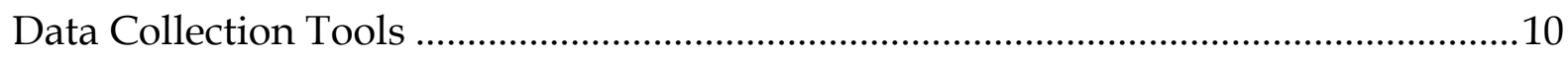

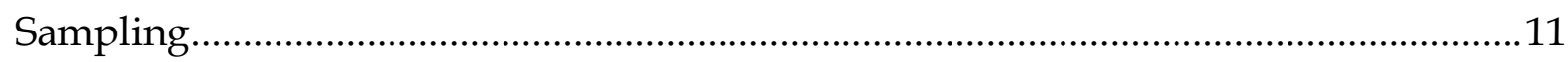

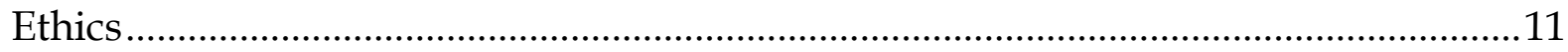

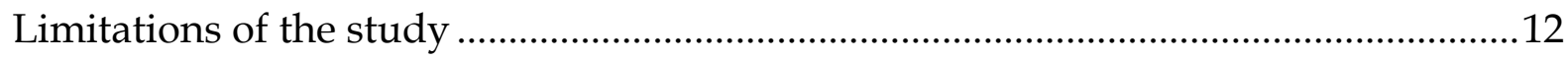

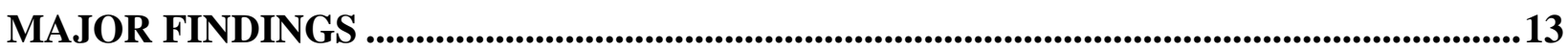

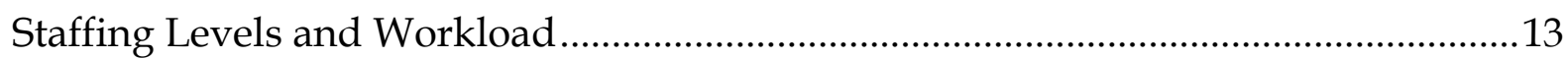

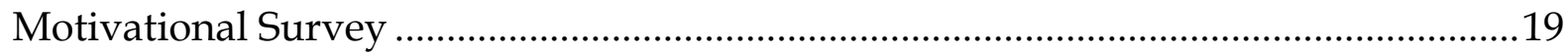

Qualitative Analysis of Open Ended Tools................................................................26

CONCLUSIONS AND RECOMMENDATIONS......................................................................34

Nursing Staff Dynamics In Kwa-Zulu Natal, Mpumalanga \& Limpopo.....................34

Exploring Factors Associated with Nursing Staff Dynamics .......................................36

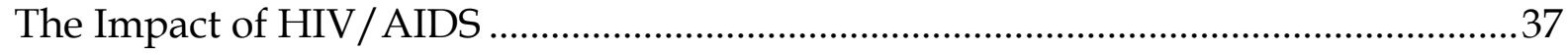

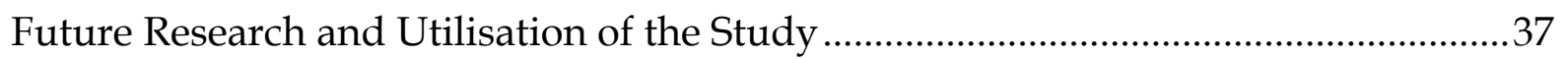

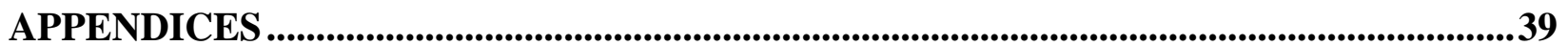

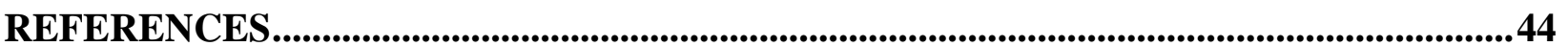




\section{LIST OF TABLES}

Table 1 Relationship between study objectives, components, data collection tools and sampling....

Table 2 Proportion of nursing posts filled at hospitals and clinics ..............................13

Table 3 Mean workloads per professional nurse per month.........................................18

Table 4 Demographic Characteristics of Professional Nurses ......................................19

Table 5 Proportion of nurses considering working overseas by demographic characteristics

Table 6 Proportion of nurses considering working overseas by motivational variables.

Table 7 Multivariate analysis of factors associated with burnout/demotivation, intention to leave, and organisational commitment.

Table 8 Results of the discrete choice experiment showing attributes/factors that would influence choice to work in a particular facility 


\section{LIST OF FIGURES}

Figure 1 Map of South Africa showing the nine provinces........................................ 2

Figure 2 Factors or attributes of facilities used in the Discrete Choice

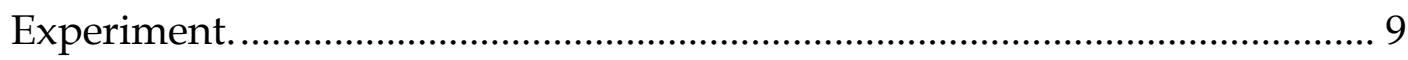

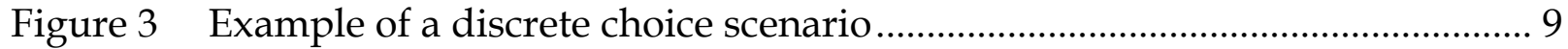

Figure 4 Proportion of Facilities Deploying Advanced Midwives (AMW).............. 15

Figure 5 Box plots illustrating mean and range of years sisters- in-charge of maternity had been in post...................................................................... 16

Figure 6 Proportion of hospitals reporting issues adversely affecting staffing in maternity wards

Figure 7 Selected motivational responses of nurses in maternity wards and clinics

Figure 8 Selected determinants of motivation among professional nurses

Figure 9 HIV/AIDS-related determinants of motivation amongst professional nurses 


\section{ACKNOWLEDGMENTS}

Special thanks are due to all the department of health officials at the national, provincial, district and facility level that took time from their busy schedules to fill out the faxed questionnaires, take us around facilities and answer our questions during site visits. Thanks also to all the busy professional nurses who spent time filling out our self-administered questionnaire.

In addition we would like to acknowledge the role of all our colleagues at the Centre for Health Policy, both academic and administrative, for creating an environment in which good quality academic research is possible. We also need to thank to our colleagues in the Health Systems Development Programme, especially Dr Charles Hongoro. Andrea Meeson provided editorial assistance.

In conclusion we would like to thank the South African Mission of USAID, and in particular, Dr. Melinda Wilson, for funding this project. 


\section{ACRONYMS}
AMW
Advanced midwives
ANC
Antenatal Care
$\mathrm{CEO}$
Chief Executive Officer
$\mathrm{CPN}$
Chief Professional Nurse
DENOSA Democratic Nurses Organisation of South Africa
DFID
Department for International Development (UK)
KZN
KwaZulu-Natal - One of the 9 provinces in South Africa
MMR Maternal Mortality Rate
$\mathrm{NDOH} \quad$ National Department of Health
NGO Non-Government Organisation
PMTCT Prevention of Mother To Child Transmission
PN Professional Nurse
SADHS South African Demographic \& Health Survey
SPN Senior Professional Nurse
USAID United States Agency for International Development 


\section{BACKGROUND}

Researchers at the Centre for Health Policy based at the School of Public Health at the University of the Witwatersrand in South Africa carried out this study between March 2004 and April 2005, in collaboration with the Population Council's Frontiers in Reproductive Health (FRONTIERS) Programme.

This study was formulated in response to current international academic debates about the importance of human resource issues within the health system as a whole. Maternal health-related studies carried out independently in South Africa by FRONTIERS, the National Committee on Confidential Enquiries into Maternal Deaths and the Centre for Health Policy had all also recently concluded that the deployment of human resources in maternal health services needed to be better documented and understood.

FRONTIERS, working with the KwaZulu Natal Department of Health, had recently completed a study of Antenatal Care (ANC) in rural clinics, which found that $38 \%$ of the providers interviewed at baseline (April - May 2002) and 53\% at the conclusion of the study (May - June 2003) had been working at the clinic for less than one year, while $10 \%$ and $12 \%$ had worked for less than two years (Chege et al 2003). These high rates of staff turnover fundamentally impacted on the ability of the project to introduce a revised model of ANC. The stakeholders in the project wanted to know if the high staff turnover in this area was typical of the country as a whole.

The Confidential Enquiry into Maternal Deaths in South Africa, 'Saving Mothers Report' (NDOH, 2003), identified poor provider practice as contributing to more than $50 \%$ of maternal deaths, with the majority of problems being at the primary health care level. In response to these findings, the National Department of Health $(\mathrm{NDOH})$ was interested to learn the degree to which staffing levels, staff turnover and other staffing issues contributed to poor practice. One of the ten key recommendations of the 'Saving Mothers Report' was the development of staffing norms for maternal health services, and the $\mathrm{NDOH}$ asked for assistance in exploring these issues in order to help them move towards developing staffing norms.

Researchers at the Centre for Health Policy, as part of the DFID-funded Health Systems Development Project, have been using maternal health services in South Africa as a probe to better understand the functioning of the health system as a whole. A key finding of this work was that it was important not just to look at numbers but also to try to understand factors that shaped provider practice and why health care workers were leaving maternal health services. To do this more attention needed to be paid to understanding relationship issues and motivation among staff working at a range of levels within maternal health services.

This study sought to develop approaches and methodologies to address these human resources questions in an interrelated way. The study was designed to try to move from what, at times, seems to be an overwhelming problem towards identifying areas for possible intervention. 
The study was carried out in three provinces in South Africa. The provinces selected reflect priority provinces of the $\mathrm{NDOH}$ and provinces that had existing relationships with the FRONTIERS programme. The three provinces selected were KwaZuluNatal, Mpumalanga and Limpopo. These provinces, illustrated in Figure 1, are predominately rural and some of the poorest in South Africa.

Figure 1 Map of South Africa showing the nine provinces

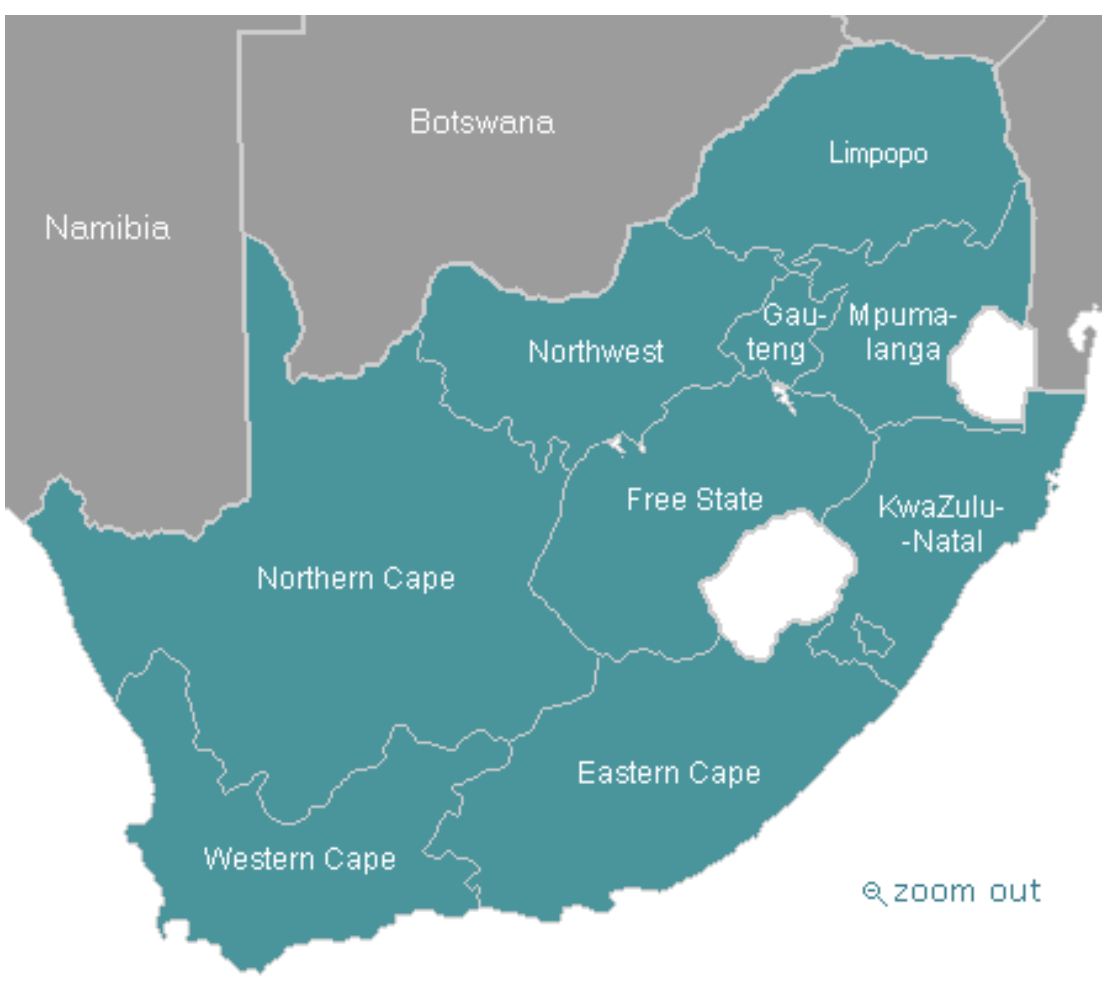




\section{STATEMENT OF THE PROBLEM}

\section{Poor Maternal Health Outcomes in South Africa}

In terms of maternal mortality, South Africa performs poorly compared to other middle-income countries, although better than much of sub-Saharan Africa. The South African Demographic and Health Survey (SADHS) estimated a maternal mortality ratio (MMR) of 150 per 100,000 live births (NDOH, 2001), and the latest Report on the Confidential Enquiry into Maternal Deaths estimates a MMR of about 175-200 per 100,000 (NDOH, 2003). These MMR levels are particularly poor considering that South Africa does well in terms of meeting UNICEF/WHO/UNFPA process indicators for preventing maternal deaths (UNICEF, WHO, UNFPA, 1997). Utilisation of maternal health services is high, with an estimated $95 \%$ of women attending ANC, and $84 \%$ of women delivering in a medical facility with skilled assistance (NDOH, 2001). South Africa, in addition, has a considerable medical infrastructure, with an estimated 4.1 facilities per 500,000 of the public sector-dependent population providing comprehensive essential obstetric care (Penn-Kekana \& Blaauw, 2002).

The NDOH has attempted to standardise clinical treatment throughout the country by producing national guidelines and a national maternity record, reflecting the latest evidence-based knowledge. These guidelines and maternity records have been widely distributed in the public sector in South Africa. Since 1994, health care for pregnant women has been free in the public sector, and South Africa has liberal abortion laws. All of these factors should have enabled South Africa to lower its maternal mortality ratio.

In addition, there is widespread evidence of poor quality of care being given routinely to women in maternity services. Jewkes et al (1998), carrying out research in Midwife Obstetric Units (MOUs) in Cape Town, found an environment "strongly characterised by humiliation of patients and physical abuse." A number of other studies have found similar findings (Smith \& Brown, 2001, Fonn et al, 1998). During the key informant interviews at the preparatory stage of this study, several informants expressed concern about the number of cases of nursing malpractice in maternity sections that came before the South African Nursing Council.

A number of factors have been suggested to explain the high level of maternal mortality and poor quality of care in South African public facilities. One explanation for the high maternal mortality rate is the impact of the HIV/ AIDS epidemic, which is now the leading cause of maternal deaths in South Africa (NDOH, 2003). The extreme patterns of inequality that exist in the provision and utilisation of maternal health services in South Africa between racial groups, mainly as a result of the legacy of apartheid, also play a role. National statistics hide a wide variation in utilisation and outcome indicators. For example, up to $40 \%$ of the poorest women in KZN province do not access ANC or give birth in facilities (Blaauw \& Penn-Kekana, 2003). Maintaining and improving health services in the context of societal and health system reform is also challenging. 
One of the most prominent discourses currently used to explain problems with the quality of provider care, however, is that staff are 'haemorrhaging' from hospitals, leaving those that remain overworked and burnt out (Padarath et al, 2004). The degree to which staff are actually overworked, and the extent to which this explains and excuses poor quality of care, has been raised by the National Confidential Enquiry into Maternal Deaths, as well as by the South African Nursing Council. In response to this issue there have been a number of calls (including a recommendation by the Saving Mothers Reports in 1998 and 2002) for the NDOH to develop staffing norms for maternal health services (NDOH 2003).

\section{Human Resource Issues}

Problems with the quality of health care, and the extent to which such problems are caused by either a lack of staff and/or demotivated staff, is not a debate unique to maternal health services, or to South Africa. Human resources in heath systems have been receiving increasing attention nationally and internationally in the last few years. It has been argued that human resource issues have previously been largely ignored, or reduced to a question of numbers, and a much broader understanding including factors that motivate staff need to be explored (Hongoro \& McPake, 2004). It is now being argued that one of the constraints in reaching many of the key health Millennium Development Goals, including reducing maternal mortality, is poorly functioning health systems in much of the developing world, with one of the main problems being "shortfalls in the health workforce" (Travis et $a l, 2004)$. One of the important factors blamed for this shortfall is the 'brain drain' of staff from African countries to countries in the more developed world (Mensah et al, 2005, Marchal \& Kegels, 2003, Buchan \& Sochalski, 2004). The fact that large numbers of South African nurses are working overseas, particularly in countries such as Ireland and the UK, is not disputed, although it has been acknowledged how difficult it is to quantify these flows of nurses (Stilwell et al 2004). A number of papers have attempted to theorise the 'push' and 'pull' factors that lead to nurses working in other countries (Buchan \& Sochalski 2004, Lehman \& Sanders 2004, Padarath 2004). However, there has been relatively little empirical research in South Africa that documents the extent to which nurses are going overseas, the impact this is having on health services, or explores the contributing factors.

When it came to power in 1994 the ANC government was faced with a health department that served the interests of the white minority, and this was reflected in the distribution of facilities and human resources. The Pick Report published in 2001 described "complex distortions of supply, production, distribution and development of health personnel." In terms of nursing, it found "no uniformly applied staffing ratios in health facilities" and "striking inequalities between urban and rural facilities" (Pick et al, 2001). The NDOH has implemented a range of actions to try to address these imbalances including: importing doctors, particularly from Cuba; introduction of community service for doctors and other health professionals, including nurses; and introduction of 'scarce skills' and 'rural' allowances in 2003. Despite these actions, there have been criticisms that human resource planning has been relatively haphazard, and the problem remains of maldistribution of health 
personnel between provinces, and between the public and private sectors (Lehmann \& Sanders, 2004). The NDOH is currently in the process of developing a human resource strategy.

\section{The Impact of HIVIAIDS}

It is not possible to discuss any issue related to health in South Africa without considering the impact of the HIV/ AIDS epidemic. It is increasingly recognised that the impact of HIV/AIDS on health systems and the health workforce is potentially catastrophic (Tawfik L \& Kinoti S, 2003). In a report commissioned by USAID looking at the impact of HIV/AIDS, the authors point out that the health system is threatened in two ways: firstly due to increased demands for services, but also because "the impacts of the epidemic on the health workforce include attrition due to illness and death, absenteeism, low morale, increased demand for provider time and skills" (Tawfik L \& Kinoti S, 2003 p.1).

Other problems identified include the diversion of resources, budgetary and managerial inadequacies, and other effects of managing systems under stress. Another issue that has emerged recently is that efforts to roll-out ART treatment in sub-Saharan Africa could drain resources, both human and financial, from other elements of the health system. For example, health workers are being recruited to work for better funded and better equipped ART clinics (McCoy et al, 2005).

A number of studies have tried to quantify the impact on health care workers both in terms of their own health and their workload. A study completed by the HSRC in 2004 found that $40 \%$ of all hospital inpatient stays were related to HIV / AIDS. It is difficult to assess if the workload is increasing overall, or if people suffering from non-AIDS-related illness are being pushed out of the health system. In terms of health care workers, the study estimated that $15,7 \%$ of health care workers working in the Free State, Mpumalanga, KZN and North West provinces were living with HIV/AIDS (Shisana et al, 2002).

\section{Maternal Health Services as a Probe to Understand Reproductive Health Services as a Whole}

Maternal health services, like all reproductive health services as a whole are provided as part of an integrated health care package, and not as a stand-alone service. Many of the same staff that provide maternal health services also provide other reproductive health services, such as STI treatment and contraceptive services. This study focused on maternal health services, which require functioning clinics and hospitals, and includes the delivery of other reproductive health services such as contraceptive services, STI treatment and VCT. Maternal health was used as a probe to gain insight into nursing staff dynamics in reproductive health services, and the health system as a whole. Maternal health services were also chosen to reflect the fact that reducing maternal mortality and morbidity are priorities of the NDOH and all provincial departments of health, and because of the perception by the researchers in the project that maternal health has been relatively neglected in recent years. 


\section{STUDY METHODOLOGY}

\section{Objectives of the Study}

The overall aim was to explore nursing staffing dynamics in maternal health services and to provide provincial departments of health and the $\mathrm{NDOH}$ with research findings that would be useful in terms of addressing human resource challenges that they face in providing good quality maternal health services in South Africa.

The specific objectives of the study were:

- To assess and document the magnitude of maternal health nursing staff dynamics in KwaZulu-Natal, Mpumalanga, and Limpopo provinces;

- To explore and document factors associated with the staffing dynamics, including HIV/AIDS, in these provinces;

- To explore and document the impact of the nursing staff dynamics on quality of care;

- To review current and possible policy and programme interventions that aim to tackle problems of staffing dynamics; and

- To start to build consensus between key stakeholders on how to address the problems identified in the research.

\section{Study Components}

As shown in Table 1 below, the overall study was divided into four component studies, as well as a preparatory phase and feedback phase. Each component was developed to provide information on one or more of the key objectives of the study. These four components were: an assessment of staff workload and turnover; a motivational survey; a discrete choice experiment; and a qualitative analysis of openended questions. Three data collection tools were used: a self-administered questionnaire for professional nurses; self-administered questionnaires sent by fax to hospitals; and interview schedules for site visits to hospitals and clinics. Data collection for the different components was frequently combined on the same data collection tools. For example, the self-administered questionnaire collected data for both the motivational tool and the discrete choice analysis components of the study. 
Table 1 Relationship between study objectives, components, data collection tools and sampling

\begin{tabular}{|c|c|c|c|}
\hline Objectives & Study Component & $\begin{array}{c}\text { Data Collection } \\
\text { Tool }\end{array}$ & Sample \\
\hline $\begin{array}{l}\text { To assess and document the } \\
\text { magnitude of maternal health } \\
\text { nursing staff dynamics }\end{array}$ & $\begin{array}{l}\text { Staff turnover and } \\
\text { workload } \\
\text { Qualitative analysis } \\
\text { of open ended } \\
\text { questions } \\
\text { Motivational Survey }\end{array}$ & $\begin{array}{l}\text { Fax } \\
\text { Questionnaire } \\
\text { Site visit tool for } \\
\text { clinics and } \\
\text { hospitals } \\
\text { Fax } \\
\text { Questionnaire } \\
\text { Site visit tool for } \\
\text { clinics and } \\
\text { hospitals } \\
\text { Self-administered } \\
\text { questionnaire }\end{array}$ & $\begin{array}{l}\text { All hospitals providing maternity } \\
\text { services in } 3 \text { provinces } \\
5 \text { hospitals and } 9 \text { clinics per } \\
\text { province } \\
\text { All hospitals providing maternity } \\
\text { services in } 3 \text { provinces } \\
5 \text { hospitals and } 9 \text { clinics per } \\
\text { province } \\
\text { All professional nurses working in } \\
\text { maternity ward or clinic at time of } \\
\text { site visit }\end{array}$ \\
\hline $\begin{array}{l}\text { To explore and document } \\
\text { factors associated with the } \\
\text { staffing dynamics, including } \\
\text { HIVIAIDS }\end{array}$ & $\begin{array}{l}\text { Motivational Survey } \\
\text { Discrete Choice } \\
\text { Experiment } \\
\text { Qualitative analysis } \\
\text { of open ended } \\
\text { questions }\end{array}$ & $\begin{array}{l}\begin{array}{l}\text { Self-administered } \\
\text { questionnaire }\end{array} \\
\text { Self-administered } \\
\text { questionnaire } \\
\text { Fax } \\
\text { Questionnaire } \\
\text { Site visit tool for } \\
\text { clinics and } \\
\text { hospitals }\end{array}$ & $\begin{array}{l}\text { All professional nurses working in } \\
\text { maternity ward or clinic at time of } \\
\text { site visit } \\
\text { All professional nurses working in } \\
\text { maternity ward or clinic at time of } \\
\text { site visit } \\
\text { All hospitals providing maternity } \\
\text { services in } 3 \text { provinces } \\
5 \text { hospitals and } 9 \text { clinics per } \\
\text { province }\end{array}$ \\
\hline $\begin{array}{l}\text { To explore and document the } \\
\text { impact of nursing staff } \\
\text { dynamics on quality of care }\end{array}$ & $\begin{array}{l}\text { Qualitative analysis } \\
\text { of open ended } \\
\text { questions }\end{array}$ & $\begin{array}{l}\text { Fax } \\
\text { Questionnaire } \\
\text { Site visit tool for } \\
\text { clinics and } \\
\text { hospitals }\end{array}$ & $\begin{array}{l}\text { All hospitals providing maternity } \\
\text { services in } 3 \text { provinces } \\
5 \text { hospitals and } 9 \text { clinics per } \\
\text { province }\end{array}$ \\
\hline $\begin{array}{l}\text { To review current and possible } \\
\text { policy and programme } \\
\text { interventions that aim to tackle } \\
\text { problems of staffing dynamics }\end{array}$ & $\begin{array}{l}\text { Qualitative analysis } \\
\text { of open ended } \\
\text { questions } \\
\text { Motivational Survey }\end{array}$ & $\begin{array}{l}\text { Fax } \\
\text { Questionnaire } \\
\text { Site visit tool for } \\
\text { clinics and } \\
\text { hospitals } \\
\text { Self-administered } \\
\text { questionnaire }\end{array}$ & $\begin{array}{l}\text { All hospitals providing maternity } \\
\text { services in } 3 \text { provinces } \\
5 \text { hospitals and } 9 \text { clinics per } \\
\text { province }\end{array}$ \\
\hline $\begin{array}{l}\text { To start to build consensus } \\
\text { between key stakeholders on } \\
\text { how to address the problems } \\
\text { identified in the research }\end{array}$ & $\begin{array}{l}\text { Preparatory Phase } \\
\text { Feedback Phase }\end{array}$ & N/A & $\mathrm{N} / \mathrm{A}$ \\
\hline
\end{tabular}




\section{Preparatory Phase: Literature Review, Key Informant Interviews and Engagement}

The project began with a breakfast meeting at the 23rd Priorities in Perinatal Care Conference in March 2004. This meeting was attended by over 50 people, who included health officials from the provincial departments and the national department of health, researchers in the field of maternal and perinatal health, and practitioners (both midwives and obstetricians). People who attended the meeting raised problems that they faced, and a range of issues that they felt needed to be addressed by the research project. In addition, key informant interviews were undertaken with 17 officials in the national and provincial departments of health, the public service commission, the Nursing Council, and Democratic Nurses Organisation of South Africa (DENOSA), and a literature review of both published and grey material was also carried out.

\section{Component One: Staff Turnover and Workload}

Data for this component were obtained from the questionnaires faxed to hospitals that provide maternity services in the three provinces, as well as from site visits. Data were obtained from the 49 hospitals that returned the fax questionnaires, as well as from site visits to 15 hospitals and 27 clinics.

\section{Component Two: Motivational Survey}

A conceptual model of the outcomes and determinants of motivation was developed for this component of the study (Appendix 1), drawing mainly on the work of Bennet et al (2001). The conceptual framework was used to define 20 domains of interest for the motivational survey, 7 concerned with the outcomes of motivation and 13 related to factors influencing motivation. Fifty-two questions were selected from existing organisational survey tools (Price, 1997) or developed to cover the domains of interest (Appendix 1). Respondents were required to identify how strongly they agreed or disagreed with each statement using a 5-point Likert scale. The pilot study was used to refine the selection and wording of the questions.

The collected data was analysed in SPSS. The internal consistency of the questions in each domain was measured by calculating Cronbach's alpha, and Factor Analysis was used to evaluate whether or not the identified domains were valid and separate constructs. Subsequent analysis explored bivariate and multivariate relationships between motivational outcomes and determinants using different codings of the responses. Variables were analysed using the original Likert coding (ordinal analysis), recoded as binary categorical variables (agree compared to not sure and disagree), and as numerical indices derived from the Factor Analysis. The results obtained by these different methods were very similar.

\section{Component Three: Discrete Choice Experiment}

Conjoint analysis was initially developed to quantitatively evaluate how different product attributes affect consumer choices but is increasingly being used to assess patient preferences for health care service delivery (Ryan \& Farrar, 2000). We utilised 
a discrete choice experiment, a form of conjoint analysis, to evaluate the relative importance of the different factors affecting maternal health nurses' choices about where to work.

We conducted focus group discussions with nurses to select five key facility characteristics to include in the analysis and to define the appropriate levels for each attribute (Figure 2). In a discrete choice experiment, respondents are asked to choose between alternatives made up of different combinations of the product attributes. A total of 48 different facility profiles can be constructed from the attributes and levels shown in Figure 2, but we used SPSS Orthoplan to select 16 of these profiles to produce an orthogonal fractional factorial study design.

Figure 2 Factors or attributes of facilities used in the Discrete Choice Experiment.

\begin{tabular}{|c|c|c|c|c|}
\hline Salary & Social Amenities & Equipment & Staffing & Facility Mx \\
\hline $\begin{array}{l}\text { - Same } \\
\text { - 15\% More } \\
\text { - Double }\end{array}$ & $\begin{array}{l}\text { - Under-developed } \\
\text { - Developed }\end{array}$ & $\begin{array}{l}\text { - Fully equipped } \\
\text { - Poorly equipped }\end{array}$ & $\begin{array}{l}\text { - Well staffed } \\
\text { - Understaffed }\end{array}$ & $\begin{array}{l}\text { - Poor } \\
\text { - Good }\end{array}$ \\
\hline
\end{tabular}

The profiles were then organised into 15 choice pairs and included in the selfadministered questionnaire. An example of one of the choice tasks is shown in Figure 3 . The collected data was analysed by multiple regression using a random effects ordered probit model in Stata 7.0.

Figure $3 \quad$ Example of a discrete choice scenario

\begin{tabular}{|l|l|l|}
\hline \multicolumn{1}{|c|}{ Facility Attributes } & \multicolumn{1}{|c|}{ Facility A } & \multicolumn{1}{c|}{ Facility B } \\
\hline Salary \& Benefits & $\begin{array}{l}\text { The salary and benefits are 15\% } \\
\text { more than you are earning now }\end{array}$ & $\begin{array}{l}\text { Pays the same salary \& benefits } \\
\text { as you are earning now }\end{array}$ \\
\hline Social amenities & $\begin{array}{l}\text { The facility has no cell phone } \\
\text { range, a dirt road, and no school } \\
\text { and shopping centre nearby }\end{array}$ & $\begin{array}{l}\text { The facility has cell phone range, a } \\
\text { tarred road, a school and shopping } \\
\text { centre nearby }\end{array}$ \\
\hline Equipment & The facility is fully equipped & The facility is fully equipped \\
\hline Staffing & The facility is well staffed & The facility is understaffed \\
\hline Management & $\begin{array}{l}\text { The facility has poor, unsupportive } \\
\text { and unfair management }\end{array}$ & $\begin{array}{l}\text { The facility has good, supportive } \\
\text { and fair management }\end{array}$ \\
\hline \multicolumn{4}{|l}{} \\
Which facility would you prefer to work at? [Please Tick one box]
\end{tabular}

\section{Component Four: Qualitative analysis of open-ended questions.}

Five open-ended questions were included in the faxed questionnaire to hospitals, as well as in the tool for hospital and clinic site visits:

1. Why are nurses leaving public health facilities?

2. What is being done to try to retain staff at facility, district, provincial and national levels?

3. What would you recommend to try to retain staff? 
4. What is the impact of HIV/AIDS on nursing staff dynamics?

5. What is the impact of nursing staff dynamics on the quality of care that is being provided in the maternity services in this hospital?

We also included questions in the sections of the faxed questionnaire collecting data on nursing staff dynamics that gave people the opportunity to give comments on these issues. In the faxed questionnaire these questions were asked of the nursing manager $^{2}$ as well as the sister-in-charge of maternity services. During the site visits to the hospitals the CEO, nursing manager, and sister-in-charge of maternity services were interviewed using these questions as the basis for the interview. The narrative data from these sections of the questionnaires were entered and thematically analysed using Atlas-ti software.

\section{Feedback Phase: Workshops at Provincial \& National Level}

Feedback workshops were held in all three study provinces, as well as at the national level. Officials from several different directorates in national and provincial departments of health, as well as academics, practitioners, nursing organisations and people working in the NGO sector, attended these workshops. These sessions were used to generate debate among participants, and suggestions about the way forward made at these workshops have been incorporated into the conclusion and recommendations sections of this report.

\section{Data Collection Tools}

\section{Fax Questionnaire To Hospitals}

Hospital Questionnaires were faxed to all hospitals providing maternity services in the three provinces selected. These questionnaires included sections on staffing levels workload, absenteeism, as well as the five open-ended questions. We collected information on staff allocation for the hospital for all levels of nurse, and nurses employed to calculate the hospital vacancy rate. At least three follow-up calls were made to each facility to increase return rates. Data were collected about the hospital as a whole, as well as about the maternity section of the hospital.

\section{Hospital Site Visit Data Collection Tool}

This tool was an expanded version of the fax questionnaire to hospitals, exploring the same issues but in more detail. Data were collected on the hospital as a whole as well as the maternity section of the hospital.

\footnotetext{
2 In the past the senior nurses in a facility who were in-charge of nursing management were known as Matrons. This term is still used in everyday language, but the official title is now Nursing Managers.
} 


\section{Clinic Data Site Visit Collection Tool}

This tool collected data on the clinic as a whole, and not specifically maternal health services. Sections were included on staffing levels and workload, as well as openended questions.

\section{Self-Administered Questionnaires}

The self-administered questionnaires were divided into three parts. The first part collected demographic data, the second part asked 52 motivational questions using 5-point Likert scale responses. The motivational questions are listed in Appendix 2). The final part of the questionnaire was a discrete choice experiment.

\section{Sampling}

The provinces were chosen on the basis that FRONTIERS was already working in the province, or they were provinces identified as needing assistance by the National Department of Health. In all three provinces, one provincial hospital, one regional hospital, three district hospitals, and nine clinics were sampled. Multi-stage cluster sampling was used to select facilities. One provincial and one regional hospital were randomly sampled in each province. Three district hospitals were then randomly sampled from facilities referring to the selected regional hospitals. Nine clinics were sampled from the same district. If facilities declined to participate they were replaced by other facilities in the same sampling frame.

The sampling method used for professional nurses was that all professional nurses working in the maternity section when the site visit was made were asked to fill in a self-administered questionnaire. During clinic visits, all professional nurses on duty in the clinic on the day of the visit were asked to fill in the self-administered questionnaire.

\section{Ethics}

\section{Ethical Clearance}

Ethical clearance for this study was obtained from the Human Research Ethics Committee (Medical) at the University of the Witwatersrand. Both Mpumalanga and Limpopo province have research ethics committees and both of these gave permission to carry out the study. The heads of the health department in all three provinces gave permission for the study to be carried out in their respective provinces.

\section{Confidentiality}

Because of the sensitive nature of some of the information collected, all data collected have been stored, analysed and reported in formats that do not allow identification of the individual participants or facilities. 


\section{Compensation}

No compensation was given to nurses or others for participating in in-depth interviews or other data collection methods.

\section{Informed Consent}

Using a structured written consent form, all people who were interviewed or filled in the self-administered questionnaire were informed about the study objectives, procedures, benefits and risks. They were assured that should they agree to participate in the study, they had the right to withdraw at any point in time and that they could refuse to answer any or all of the questions, even after consenting to participate in the study. If they did not wish to participate they were assured that it would have no implications for them. Care will be taken to ensure that respondents' confidentiality was maintained throughout.

\section{Limitations of the study}

Although this project focused on maternal health services, due to the integrated nature of maternal health services in the South African health system many of the nursing staff dynamics, and motivational determinants and outcomes measured and explored are not specific to maternal health services. Although this could be interpreted as a limitation of this study, it is also a strength. The study was always intended to use maternal health services as a probe for understanding nursing staff dynamics in reproductive health services, and the health system more widely.

As the three provinces were not randomly sampled it is not possible to generalise the findings from these three provinces to other provinces or to the whole of South Africa. A return rate of $62 \%$ from the facilities was achieved in the three provinces; despite at least three follow up telephone calls to facilities, which may also have introduced a selection bias into the data. It may be that the better-staffed hospitals had the time available to collect the data and fill in the questionnaire. It should also be noted that data from the self-administered questionnaires reflect nurses' intentions rather than an objective measure of nurses' actual practice. Staff interviewed were those who were continuing to work in a facility, and therefore may have experiences and perceptions that differ from those nurses who have left.

This study, as with any other study of facilities in the public health sector, was forced to rely on hospital and clinic routine data that is not always of a good quality. As well as routine data from facilities, it was planned to include an analysis of the human resource database for the three provinces. Permission to use this database was granted by the $\mathrm{NDOH}$, but due to a range of issues at the $\mathrm{NDOH}$, and beyond the control of the researchers, this data set was not made available during the study period. 


\section{MAJOR FINDINGS}

\section{Staffing Levels and Workload}

Results presented in this section were collected in the faxed questionnaire to hospitals as well as during the site visits to the sampled hospitals and clinics.

\section{Vacant Posts}

Table 2 shows that across the three provinces the vacancy rates for professional nurses were $22.6 \%$ in hospitals and $26.5 \%$ in clinics. Limpopo had less of a problem in its hospitals and clinics, whereas KZN had problems in both its hospitals and clinics, with the vacancy rate standing at about 30\%. Mpumalanga had a serious problem with vacancies at its clinics. Two of the clinics visited had only one professional nurse, and both reported that there were periods in the last year, mainly when they had taken annual leave, during which the clinic operated with no professional nurse at all.

In $\mathrm{KZN}$ and Limpopo vacancies were most severe at the professional nurse level. In Mpumalanga there also appeared to be many vacancies for non-professional nurses at the clinics.

Table 2 Proportion of nursing posts filled at hospitals and clinics

\begin{tabular}{|l|r|r|r|r|}
\cline { 2 - 5 } \multicolumn{1}{c|}{} & \multicolumn{4}{c|}{ \% Posts filled (mean \pm standard deviation) } \\
\cline { 2 - 5 } \multicolumn{1}{c|}{} & \multicolumn{1}{c|}{ KZN } & \multicolumn{1}{c|}{ Limpopo } & \multicolumn{1}{c|}{ Mpumalanga } & \multicolumn{1}{c|}{ Total } \\
\hline Professional & & & & \\
nursing posts & & & & \\
Hospitals (n=59) & $70.9 \pm 20.5$ & $85.8 \pm 13.1$ & $78.7 \pm 21.1$ & $77.4 \pm 19.4$ \\
Clinics (n=24) & $71.0 \pm 28.7$ & $90.6 \pm 18.6$ & $57.4 \pm 16.3$ & $73.5 \pm 25.4$ \\
All nursing posts & & & & \\
Hospitals ( $n=59)$ & $78.0 \pm 13.6$ & $80.4 \pm 14.7$ & $82.2 \pm 25.2$ & $79.7 \pm 16.9$ \\
Clinics (n=24) & $67.6 \pm 25.0$ & $91.1 \pm 17.3$ & $64.9 \pm 19.8$ & $74.7 \pm 23.6$ \\
\hline
\end{tabular}

A number of facilities reported that their staffing allocation was going through a period of change, reflecting a re-organisation of services in their province. Some clinic managers were also unsure of what their staffing level was. Many facilities were in the position of having sufficient, or even above the allocated number of chief professional nurses (CPNs), but had insufficient senior professional nurses (SPNs) and Professional Nurses (PNs).

This section of the questionnaire also contained an open-ended question where managers were able to provide comments on the nursing staff dynamics data that we were collecting. At most of the facilities, managers had little idea about who had made the allocations of posts to their hospital, or on what basis these allocations had been made. Most felt that the allocation of posts was not sufficient for the workload 
being experienced by the facility and reported that they had, or were in the process of, requesting the provincial department of health for more posts. It was clear, however, that they did not have solid proposals for requesting more staff. Many managers also reported that the issue of the number of posts, and at what level (which were set at the provincial headquarters) caused a great deal of tension between themselves and staff at their facility.

Managers also recounted frustration with the fact that they were powerless to fill posts, because advertising for staff at a professional nurse level is the responsibility of the provincial headquarters. Managers mentioned that they relied on staff applying of their own accord. Some nursing managers reported using informal networks, often relying on retired nurses, to try to attract nurses to apply for the posts. A frequent complaint was that nurses would apply to and go for interviews at a number of facilities, and then agree to work at more than one. Plans would be made by the facility on the basis of this acceptance, but then the nurse would not appear on the agreed date, only for the facility to discover a few months later that the nurse had accepted a job in another facility.

\section{Advanced Midwives}

The NDOH has identified advanced midwives ${ }^{3}$ as key to improving the quality of maternal health services in South Africa. Advanced midwives have completed a oneyear post-basic training in midwifery, and their scope of practice is considerably wider than nurses who have just had basic midwifery training. It is stated government policy that all facilities that carry out deliveries should have at least one advanced midwife working at the facility, and ideally one working on each shift (NDOH, 2004).

Figure 4 shows that overall, $81.3 \%$ of the hospitals had at least one advanced midwife working in the hospital. However, just over $45 \%$ of facilities had an advanced midwife working on each day shift, and only $9.4 \%$ of facilities had an advanced midwife working on each night shift.

\footnotetext{
3 Advanced midwives are professional nurses who have completed a 1-year post basic training in midwifery.
} 
Figure 4 Proportion of facilities deploying advanced midwives (AMW)

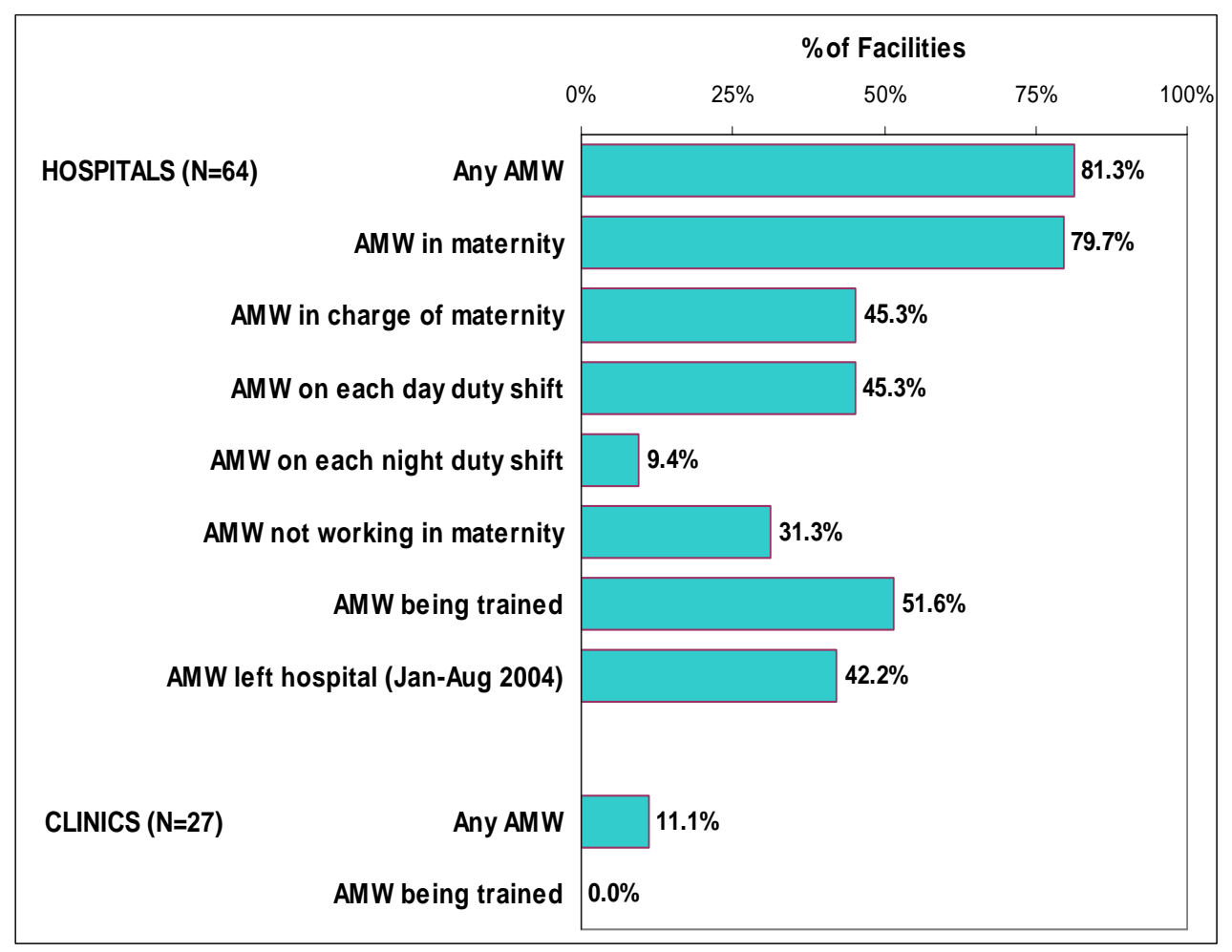

Advanced midwives were only in charge of the maternity unit in $45.3 \%$ of facilities. More than $30 \%$ of facilities had advanced midwives who were not working in the maternity section, and many of these appeared to be working in management positions. This problem is related to the fact that having post-basic training and clinical expertise were not reflected in higher levels of pay, and so ambitious, competent nurses had no other avenues for promotion apart from going into management.

Forty-two percent of facilities had lost at least one advanced midwife during the period January to August 2004. Thus 33 advanced midwives left the service, and over the same time period only 20 advanced midwives joined facilities. At facilities where site visits were made managers were asked for information on where advanced midwives who had left had gone. Of the eleven advanced midwives who had left those facilities during the specified time frame, three had gone overseas, two had gone to the private sector, two had been promoted, one had retired, one had taken early retirement due to ill health, one had transferred to another government hospital and the current location of one was unknown.

More than $50 \%$ of hospitals reported at least one member of staff was currently being trained in advanced midwifery, but no clinics were training advanced midwives. Only three of the clinics had advanced midwives working at the facility. 


\section{Sisters-in-charge in the Maternity Section and at Clinics}

The turnover rate of sisters-in-charge gives some insight into the stability of ward management. As shown in Figure 5 the average length of service of the sisters-incharge was more than five years, which indicates some degree of stability, at least in terms of management in many facilities. Some facilities reported the sister-in-charge of maternity had been in charge for more than 20 years. The longest service sistersin-charge are illustrated in the figure by confidential identification number.

Figure $5 \quad$ Box plots illustrating mean and range of years sisters-in-charge of maternity had been in post

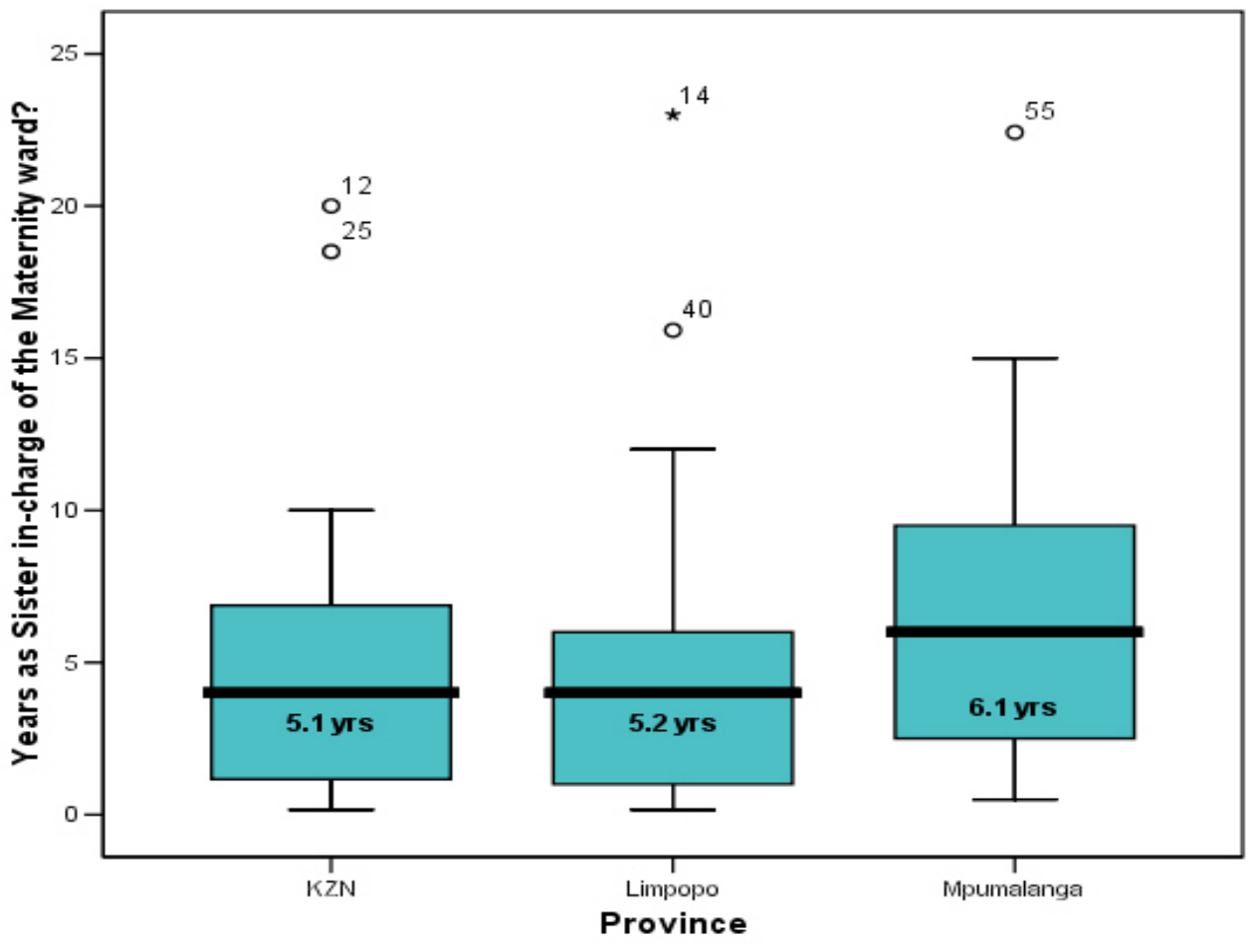

\section{Other staffing issues}

As illustrated in Figure 6, 73.4\% of hospitals regularly rotated other staff through maternity services, although this usually did not apply to nurses who had received training in advanced midwifery. This has important implications for many initiatives that attempt to train staff working in maternity services, as this practice means that staff who gain skills related to maternity services are often not working in maternity services after a few months.

Another area of concern was that most facilities reported perceiving that they often, or very often, did not have the number of staff on duty that had been allocated to the maternity section. They also reported that within the last year there have been times when staff have not been able to go on training due to shortages of personnel, with training in Voluntary Counselling and Testing (VCT), prevention of mother to child transmission, (PMTCT) and ARV provision most commonly reported as training 
that had been missed due to shortages of staff. Managers also reported that not being able to go on training adversely affected staff morale.

Figure 6 Proportion of hospitals reporting issues adversely affecting staffing in maternity wards

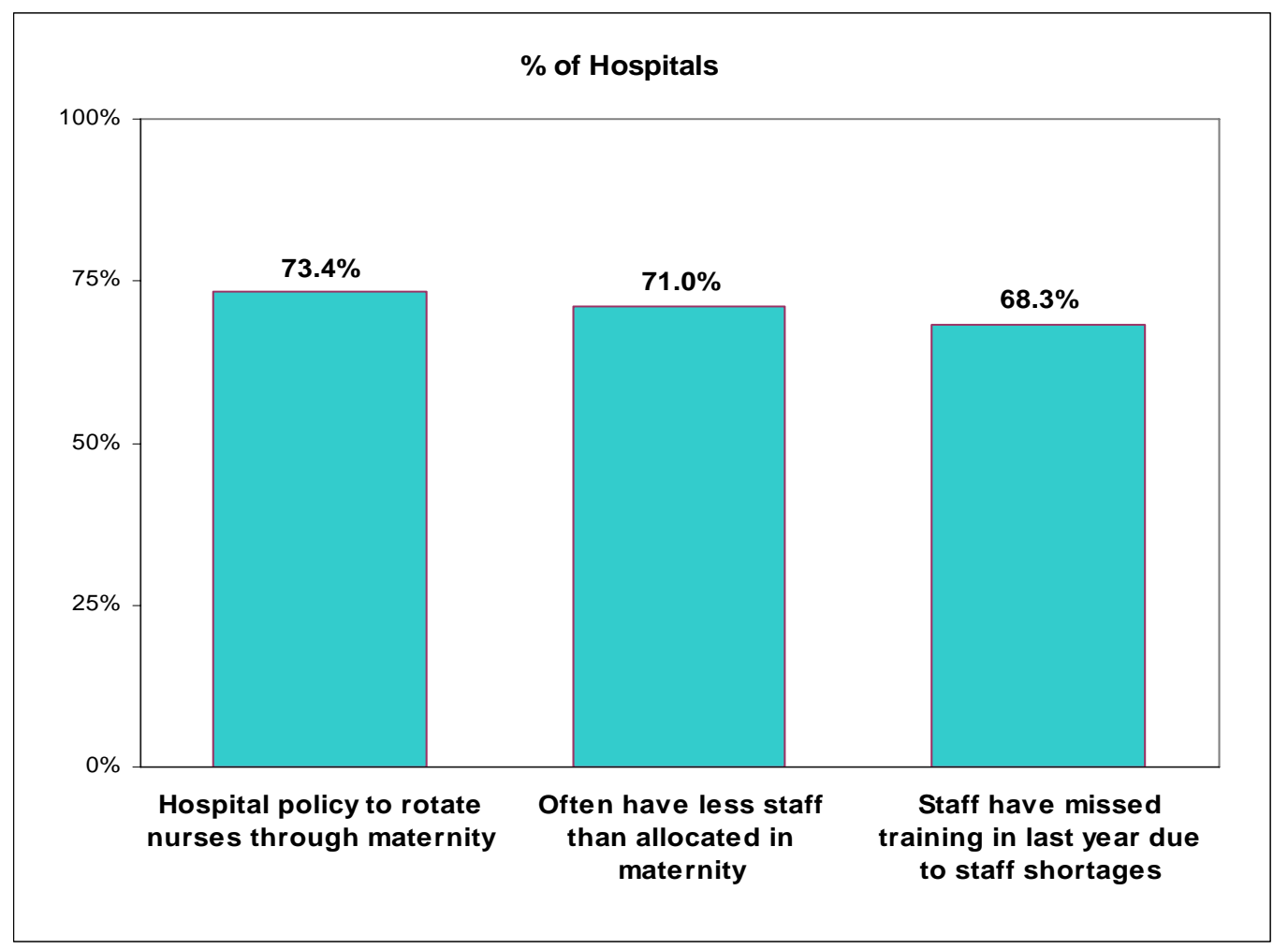

\section{Leave and duties taking staff away from facilities}

Data were collected on leave that was taken by professional nurses working in maternity sections. None of the facilities reported that professional nurses took unauthorised leave in maternity sections although this may have been a definitional problem. Professional nurses taking sick leave or personal emergency leave was a problem; overall, 11\% of available professional nurse staff days in August 2004 were lost to these unplanned periods of leave. This leave was in most cases taken in odd days, and not prolonged periods of sick leave. It was also found that $7.9 \%$ of allocated maternity staff were not in the hospital on the day the research team visited, due to duties that had taken them away from the facility, including off site training and meetings.

\section{Workload}

Data on the number of patient visits and the number of professional nurses on duty were collected for the period March to August 20044, and an average was then

4 Data could not be collected from two clinics in Mpumalanga as one professional nurse only staffed these, and both admitted that they were unable to see patients and keep up to date with record keeping. 
calculated over the six-month period. As show in Table 3, this crude calculation suggests that clinics in Limpopo had the lowest average workload, with 564 patients per professional nurse per month, and Mpumalanga had the highest workload with 1179.5 per month.

Table $3 \quad$ Mean workloads per professional nurse (PN) per month

\begin{tabular}{|l|r|r|r|r|}
\cline { 2 - 5 } \multicolumn{1}{c|}{} & \multicolumn{4}{c|}{ Workload (Mean \pm standard deviation) } \\
\cline { 2 - 5 } \multicolumn{1}{c|}{} & \multicolumn{1}{c|}{ KZN } & \multicolumn{1}{c|}{ Limpopo } & \multicolumn{1}{c|}{ Mpumalanga } & \multicolumn{1}{c|}{ Total } \\
\hline Clinics (N=25) & & & & \\
Pts / PN / Month & $644.4 \pm 324.8$ & $564 \pm 195$ & $1179.5 \pm 1257$ & $\mathbf{7 7 0 . 3} \pm \mathbf{7 2 8 . 5}$ \\
Hospitals (N=56) & & & & \\
In-Pts / PN / Month & $50.5 \pm 42.6$ & $26.1 \pm 17.2$ & $23.5 \pm 14.1$ & $\mathbf{3 7 . 4} \pm \mathbf{3 3 . 9}$ \\
Deliveries / PN / Month & $16.6 \pm 10.2$ & $14.7 \pm 6.4$ & $19.5 \pm 7.7$ & $\mathbf{1 6 . 5} \pm \mathbf{8 . 7}$ \\
\hline
\end{tabular}

Calculating a crude workload in hospitals was complicated considerably by the fact that maternity services in different facilities were organised very differently. For example, in one of the hospitals sampled, critically ill women delivering were nursed in the general ICU, whereas in another hospital the maternity unit contained a two-bed maternity ICU. Hospitals also had different arrangements around care of babies, and some organised services by amalgamating staff allocations for gynaecological and maternity wards.

As Table 3 shows, the crude workload for hospitals was calculated using two different indicators: firstly by calculating the ratio of in-patients per professional nurse per day, and secondly by calculating deliveries per professional nurse per month. Data were collected, and analysed over a period of six months to compensate for monthly variations. In terms of in-patient days, the workload was considerably higher in KZN than in the other two provinces, but the workload for number of deliveries was similar between all three provinces.

Nursing managers were asked about the formula that they used to allocate staff to the maternity section. Although many indicated workload, it was clear that no definite formula was used in any of the facilities. Nurse managers reported that maternity services were a priority for the hospital in terms of allocation of staff, but sisters-in-charge of maternity services often reported that they were unhappy about the levels of staff allocated, and felt that hospital management was not sympathetic to the workload that they faced. Sisters-in-charge of maternities reported that they were often criticised for the quality of care that they provided, but that management was not sympathetic to the staffing constraints under which they operated. They also complained that other wards were better staffed and had higher priority for hospital management. 


\section{Motivational Survey}

Results presented in this section of the report are from the 52 motivational determinate and outcome questions that were included in the self-administered questionnaire, which was completed by professional nurses working in maternity wards at the time of the site visits. A complete list of the questions and results are listed in Appendix 2.

Table 4 describes the characteristics of professional nurses sampled in the hospitals and clinics. The mean years in the current facility was above nine in both KZN and Mpumalanga, and nearly six years in Limpopo. The mean age of nurses in the study was 40 years with little variation, and the majority of nurses had children under the age of 18 years. The proportion of nurses who had advanced midwifery training was highest in KZN.

Table $4 \quad$ Demographic characteristics of professional nurses

\begin{tabular}{|l|c|c|c|c|}
\cline { 2 - 5 } \multicolumn{1}{c|}{} & KZN & Limpopo & Mpumalanga & Total \\
\hline N & 67 & 46 & 34 & 147 \\
$\%$ Female & $97 \%$ & $94 \%$ & $91 \%$ & $95 \%$ \\
$\%$ Hrban & $25 \%$ & $61 \%$ & $74 \%$ & $48 \%$ \\
$\%$ Single & $64 \%$ & $44 \%$ & $44 \%$ & $53 \%$ \\
Mean Age (Yrs) & $27 \%$ & $39 \%$ & $36 \%$ & $33 \%$ \\
$\%$ with child < 18 yrs & 39.6 & 39.9 & 40.8 & 40.0 \\
Mean yrs in current facility & $67 \%$ & $71 \%$ & $68 \%$ & $68 \%$ \\
$\%$ Advanced midwife & 9.9 & 5.8 & 9.0 & 8.4 \\
\hline
\end{tabular}

\section{Motivational Outcomes}

Responses to selected questions asking professional nurses to rate their motivation suggest a problem with professional nurse morale. Figure 7 shows that $60 \%$ of professional nurses agreed or strongly agreed with the statement: "These days I don't feel motivated to work as hard as I could", and $43 \%$ agreed with the statement: "When I get up in the morning I dread having to face another day at work." More than half of the nurses supported the possibility that they would consider working overseas in the future. All of these results have serious implications for nursing in South Africa. Although seeing themselves working overseas does not automatically translate to going overseas, together with the other indicators of demotivation there should be concern that such large proportions of nurses appear to be burnt out. 
Figure 7 Selected motivational responses of nurses in maternity wards and clinics

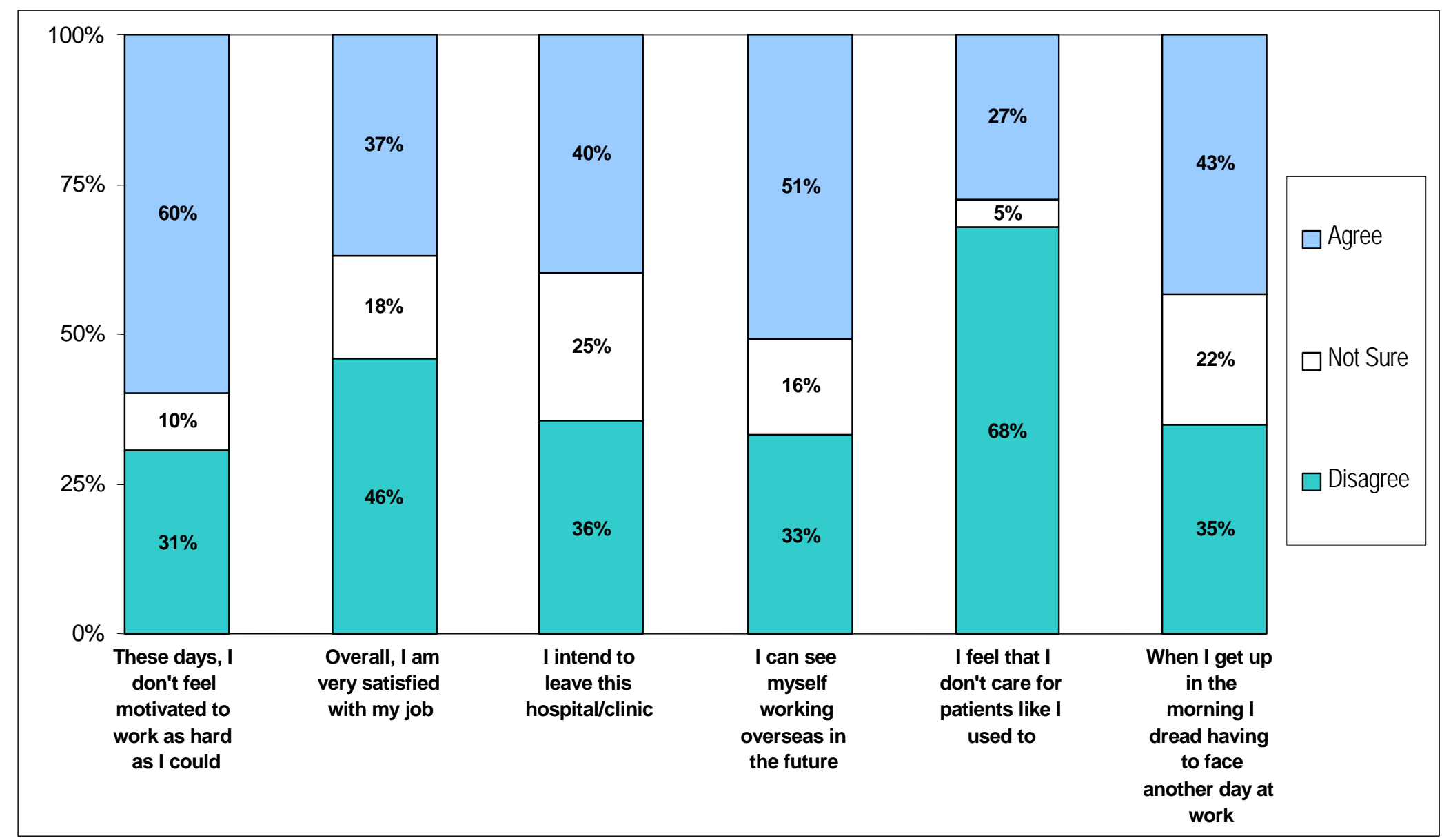




\section{Determinants of Motivation}

In terms of the factors that determine the level of motivation among professional nurses, the vast majority are confident in their ability to do their jobs, but half of them wish they had chosen another career, $65 \%$ think that they don't have promotion opportunities, $69 \%$ are worried about how to support their families; and $84 \%$ think that there are not enough staff to do the work (see Figure 8, Appendix 2).

As shown in this same figure, $40 \%$ of nurses working in the maternity section feel stressed and are thinking about transferring to another ward. Only one-half feel that they get adequate support and supervision, and one-quarter think that if they make a mistake the management will support them. More than three-quarters agreed with the statement: "The DOH does not adequately consider the effect of their decisions on staff when developing new policies." However, $66 \%$ of nurses think that doctors and nurses work well together in their facility.

HIV / AIDS has been suggested as a contributing factor to low staff morale. Figure 10, Appendix 2 shows that, in this sample of professional nurses, only $34 \%$ of nurses agreed that caring for patients with HIV / AIDS was demoralising, and only $15 \%$ agreed that the risk of catching HIV has made them think about leaving their job; indeed, more nurses (37\%) were worried about catching HIV/ AIDS outside of work.

\section{Factors associated with nurses considering working overseas}

During analysis a number of statistical models looking at the relationship between motivational outcomes and determinates were developed. Because the 'brain drain' of nurses from South Africa is a key concern of the NDOH, as well as a concern in much of the published literature on human resources in South Africa generally the results presented in this report focus on nurses who stated that they intended to leave the facility, or were considering going overseas. This study could only sample nurses who are still working in public health facilities and not those who have already gone overseas, however it still provides some useful insights. In this analysis, those nurses who said they agreed or strongly agreed with the statement that they could see themselves working overseas in the future were compared with those who were unsure and those who disagreed and strongly disagreed.

Table 5 shows there were no differences between the provinces, whether nurses worked in an urban or rural area, or in a clinic or hospital. The two factors that were significant were the nurse's age and the ages of her children. Nurses in the middle age group of 30 to 49 years were most likely to see themselves going overseas in the future. Nurses with children under 18 years were also more likely to consider going overseas, with qualitative data identifying the need for money to pay for a good quality education being a key factor in motivating them to go overseas. 
Table 5 Proportion of nurses considering working overseas by demographic characteristics

\begin{tabular}{|c|c|c|}
\hline Sub-Category & $\begin{array}{c}\% \\
\text { Agreeing } \\
\end{array}$ & $\begin{array}{l}\chi^{2} \text { Test } \\
\text { p value }\end{array}$ \\
\hline Total & $50.7 \%$ & \\
\hline Province & & \\
\hline KwaZulu-Natal & $46.9 \%$ & \\
\hline Limpopo & $60.9 \%$ & 0.235 \\
\hline Mpumalanga & $43.8 \%$ & \\
\hline Area & & \\
\hline Urban & $50.0 \%$ & 081 \\
\hline Rural & $51.5 \%$ & 0.001 \\
\hline Facility & & \\
\hline Clinic & $43.1 \%$ & 005 \\
\hline Hospital & $57.1 \%$ & 0.000 \\
\hline Age Group & & \\
\hline $20-29$ & $47.8 \%$ & \\
\hline $30-39$ & $56.3 \%$ & Oחת \\
\hline $40-49$ & $63.0 \%$ & \\
\hline $50+$ & $19.0 \%$ & \\
\hline Any children < 18yrs & & \\
\hline No & $33.3 \%$ & \\
\hline Yes & $60.0 \%$ & \\
\hline
\end{tabular}

Table 6 describes nurses considering working overseas in terms of motivational factors. The findings suggest that nurses who were unhappy about their relationships with doctors and facility management were more likely to consider going overseas, as were nurses who felt overworked and stressed with working in the maternity ward. Nurses considering going overseas also wished they had chosen another profession, and felt that the NDOH did not consider the effect of their decisions on staff when developing new policies. 
Table 6 Proportion of nurses considering working overseas by motivational variables

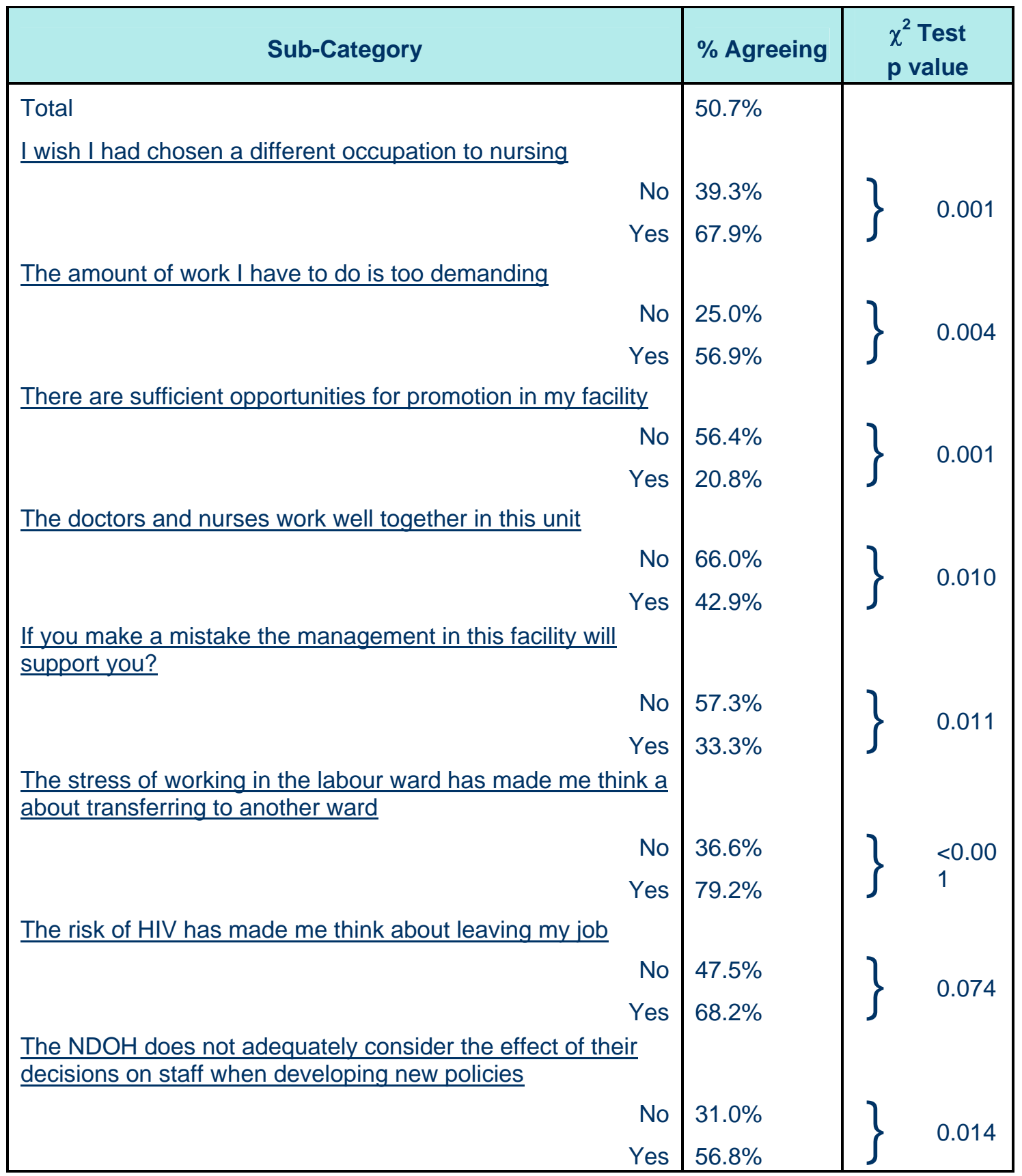

\section{Factor Analysis}

The factors produced by the factor analysis were mostly consistent with our original domains (Appendix 2[DB1]). In terms of motivational outcomes the factor analysis suggested that 'burnout' and 'demotivation' were actually one domain and that 'job satisfaction' and 'intention to leave' were similarly too closely related to be separated. Attitudes toward HIV patients did not emerge as a significant construct. Overall, the five main factors related to motivational outcomes explained $62 \%$ of the variance. 
For motivational determinates the factor analysis suggested 13 main factors, explaining $74.2 \%$ of the variance, rather than the original 14 . Nurses did not seem to distinguish between supervision and hospital management. These constructs were not separable but together constituted the most important factor determining motivation.

\section{Multivariate analysis of factors associated with motivational outcomes}

Multivariate regression analysis was used to explore the relationships between motivational outcomes and motivational determinants. In summarising the main patterns found in these analyses, Table 7 shows the results of a multiple linear regression using numerical indices for the key domains derived from the factor analysis. The table shows the significant associations between predictors (demographic variables and the 13 motivational determinant factors) and three motivational outcomes: 'burnout and demotivation', 'intention to leave' and 'organisational commitment'. Unhappiness with their vocational choices, stress at work, and not being able to cope with change were significantly related to burnout and demotivation. Younger nurses, those working in hospitals, those with young children, and those working in urban areas were more likely to report that they were thinking of leaving. Concerns about stress, pay and promotion, and relationships with co-workers were also significantly associated with the intention to leave. On the other hand, factors such as facility management, relationships with supervisors and doctors, and workload were important in determining organisational commitment. 
Table 7 Multivariate analysis of factors associated with burnout/demotivation, intention to leave, and organisational commitment

\begin{tabular}{|c|c|c|c|}
\hline & $\begin{array}{l}\text { Burnout / De- } \\
\text { motivation }\end{array}$ & $\begin{array}{l}\text { Intention } \\
\text { to Leave }\end{array}$ & $\begin{array}{c}\text { Organisational } \\
\text { Commitment }\end{array}$ \\
\hline Type of facility & & $\star \star \star *$ & \\
\hline Area & & $\star \star \star *$ & $\star \star \star \star ~$ \\
\hline Age group & & *** & \\
\hline Any children $<18$ yrs & & $* * *$ & \\
\hline Facility $\mathrm{Mx}+$ supervisor relationships & & & $\star \star * *$ \\
\hline Vocation & *** & & *** \\
\hline Stress/Work hazards & *** & *** & \\
\hline Pay and promotion & & *** & \\
\hline Co-worker relationships & & $\star \star \star *$ & \\
\hline Self efficacy & & & *** \\
\hline Nurse-doctor relationships & & & *** \\
\hline Workload & & & $\star \star \star \star ~$ \\
\hline \multicolumn{4}{|l|}{ Religious beliefs } \\
\hline \multicolumn{4}{|l|}{ Fear of assault } \\
\hline Coping with change & *** & & *** \\
\hline \multicolumn{4}{|l|}{ HIVIAIDS } \\
\hline \multicolumn{4}{|l|}{ Not able to support family } \\
\hline $\mathbf{R}^{2}$ & 0.517 & 0.513 & 0.528 \\
\hline
\end{tabular}

*** $\mathrm{P}<0.05$

\section{Discrete Choice experiment}

The results of the discrete choice experiment are shown in Table 8. All five selected factors ${ }^{5}$ were statistically significant $(p<0.001)$ in influencing maternal nurses' choices about where to work. In a discrete choice analysis the regression coefficients quantify the relative importance of each factor, and two factors can be directly compared by dividing their coefficients. Therefore, Table 8 shows that higher salaries, good facility management, and the availability of equipment were the most important determinants of nurses' hypothetical choices about where to work. Being

\footnotetext{
${ }^{5}$ Salary had three levels which were entered as two dummy variables in the regression.
} 
well staffed and having good social amenities were the least important facility characteristics in this analysis but were nevertheless significant in influencing nurses' decisions.

Table 8 Results of the discrete choice experiment showing attributes/factors that would influence choice to work in a particular facility.

\begin{tabular}{|c|c|c|c|c|}
\hline Variable & Coeff & $P$ value & $\begin{array}{l}\text { Relative to } \\
\text { Sal+15\% }\end{array}$ & $\begin{array}{l}\text { Relative to } \\
\text { Double Sal }\end{array}$ \\
\hline Salary $+15 \%$ & 0.957 & $<0.001$ & 1.00 & 0.57 \\
\hline Double salary & 1.677 & $<0.001$ & 1.75 & 1.00 \\
\hline Developed social amenities & 0.509 & $<0.001$ & 0.53 & 0.30 \\
\hline Fully equipped & 1.043 & $<0.001$ & 1.09 & 0.62 \\
\hline Well staffed & 0.564 & $<0.001$ & 0.59 & 0.34 \\
\hline Good facility management & 1.330 & $<0.001$ & 1.39 & 0.79 \\
\hline Constant & -2.67 & $<0.001$ & & \\
\hline Rho $(\rho)$ & 0.291 & $<0.001$ & & \\
\hline $\operatorname{Prob}\left(\chi^{2}\right)$ & $<0.0001$ & & & \\
\hline
\end{tabular}

The results demonstrate that both financial and non-financial factors influence nurses' choices about where to work. Having good facility management and adequate equipment were more important than getting a 15\% salary increase, or the extent of current financial incentives such as the rural allowance or scarce skills allowance. However, the fact that receiving double their current salary would be the most significant inducement to nurses' changing facility reflects that salary remains a concern for nurses.

By adding interaction terms to the regression it is possible to analyse how nurse characteristics influence these valuations. The analysis (not shown) revealed that salary levels were more important to younger nurses and nurses working in hospitals, while rural nurses were relatively more concerned about facility management.

\section{Qualitative Analysis of Open Ended Tools}

The results presented in this section are from open-ended questions that were asked in both the faxed questionnaires and site visits to ward and facility managers. At the end of the self-administered questionnaire nurses were asked if they had any additional comments. This data was also entered and analysed and has been included in some sections.

\section{Why are staff moving?}

A complex range of inter-related factors appear to be influencing nurses' movement. Movements of staff reported were multi-directional with nurses moving between 
public facilities, from the public to the private sector and overseas, as well as back to the public sector from the private sector and overseas. Some nurses reportedly moved from rural to urban facilities to get access to social amenities, to training, and to private hospitals where they can moonlight for extra income. Other nurses reportedly moved from urban to rural facilities to get the rural allowance, move to the private sector, or go overseas. However the dominant direction of the flow of staff reported was nurses leaving the public sector for overseas.

A number of nursing managers reported that going overseas has become more difficult recently, especially to the UK. Reports were also coming back of nurses being treated badly in Saudi Arabia, and managers reported that these issues were putting off nurses from going overseas. Some hospital managers also stated that nurses were returning from overseas. Others reported that staff were applying to come back to their facilities because they were unhappy in the private sector. Other nurses had reportedly cashed in their pensions and now run out of money and wanted to return to their facilities. A majority of the managers reported that the situation in terms of nursing staff leaving seemed to be better now than it was a couple of years ago.

Managers' perception of the motivation for nurses to go overseas was that it was overwhelmingly due to money, with nurses planning to go for a few years only to pay for their houses, buy cars, and pay for children's education. A small minority of nurses were 'fed up' with South Africa and wanting to immigrate.

For those moving between facilities within the public sector, issues arising included being fed up with the workload at a particular facility, and perceptions that workloads in the private sector, or at other facilities (hospital nurses said at clinics, and clinic nurses said at hospitals) were not as severe. Lack of promotion opportunities was also was mentioned, as was poor management, including inflexibility around rotations and shift allocations, and perceptions that management was punitive, unsupportive and unfair, with management's 'favourites' getting training and promotion opportunities. Also mentioned were problems with employment of other family members in the same area that they worked in, with nurses moving to places where their spouses could get employment.

\section{Issues in rural facilities}

Problems with accommodation for nurses were mentioned repeatedly as reasons why nurses were leaving, and some of the nursing homes observed during site visits were in a poor state of repair, with severe levels of overcrowding (two or three professional nurses having to share a room). At one facility a nurse, his wife and two children had to live in the nursing manager's office for several months because no other accommodation was available. Frustration was expressed that doctors appeared to have better quality housing and furnishing than nurses. Many hospital managers reported that they were in the process of either improving or building new nurse accommodations. For nurses doing their community service at health facilities, nursing managers and managers have to prove to provincial officials that they can 
provide suitable accommodation, and this seemed to motivate them to take action, including renting houses in the vicinity of hospital for nurses.

Transport was also mentioned as a problem for nurses working in rural areas. Getting to work, if they did not live in the rural area, or getting their children to school, going shopping and other personal business was problematic. Available transport was often expensive, unreliable and did not run at convenient times.

Lack of facilities for children, including access to good quality English medium schools, also emerged as an explanation for why nurses were leaving some rural facilities. Some nurses felt unsafe and wanted to leave rural facilities, as clinic and hospital grounds and the surrounding areas are often unlit, and managers reported cases of staff being robbed or raped.

\section{Skilled and hardworking staff leaving}

Some managers talked specifically about the frustrations of talented qualified nurses leaving their facilities because they often felt frustration with not being able to make changes at facilities due to resistance from other members of staff. Many hospitals had very few options for promoting staff, as they already had more CPNs than their allocation. Skilled nurses also felt frustrated when they felt that they worked harder than their colleagues and their efforts went unrewarded.

\section{What is being done to retain staff?}

At the ward and clinic levels, managers did not see themselves as having a role in retaining staff in their facilities - they identified with their staff and not as managers. In hospitals, some managers had actively addressed the issue of retaining staff, and discussed a range of policies that they were instituting in their facilities. These policies fell into two groups. First, actively promoting sports clubs, choirs and other social events in their facilities. One hospital manager indicated, however, that they were often frustrated in these attempts to improve the social environment, as they were seen as a waste of valuable resources.

Second, some managers were trying to adopt a more positive management style. They talked about an open-door policy, giving staff choices about when they were rotated and where, as well as which shifts they worked; they also talked about involving staff in decision-making. During site visits it was apparent that some hospital managers were embroiled in industrial disputes with staff. In other hospitals the hospital management appeared grossly disorganised, demotivated and planned to leave themselves. Many of these managers complained that they had no power or knowledge about how to retain staff in facilities.

A number of key initiatives at the national and provincial levels were identified. These included the scarce skills allowance, rural allowance, various award schemes, the performance management system, and what appeared to be a strong capital infrastructure improvement programme. However, at the same time as identifying strategies that were being implemented, overall the feeling that was expressed 
repeatedly was that nurses working at the facility level felt uncared for and largely forgotten.

"These nurses they get promoted to the district and the province and elsewhere in the government and they forget us. Sometimes they even forget to greet us when you see them in town. It's the same with the councillors and the politicians."

"They are doing nothing to help us on the ground. They know the conditions are hard. But they don't care ... staff are just fed up and they are leaving."

\section{Scarce skills allowance}

Nurses working in maternity services were unhappy that advanced midwifery has not been identified as a "scarce skill." Many advanced midwives reported that they had heard informally that advanced midwifery was going to be classified a scarce skill, and then were disappointed when it wasn't. The fact that advanced midwives do not get a scarce skill allowance seems to have had two effects. First, advanced midwives interpreted it as the NDOH not prioritising maternity services: "it shows they don't care about us midwives." Second, nursing managers reported that staff were not requesting to be trained as advanced midwives, but in other post-basic skills that do receive the scarce skills allowance.

"Nurses are now writing motivations to be trained in intensive care nursing or oncology nursing, even though it's not relevant for this hospital"

Nursing Manager

A number of nurses also stated their resentment about the fact that doctors and other allied professionals get the scarce skills allowance but they do not.

\section{Rural allowance}

The rural allowance was extensively discussed, and responses were mixed about its effectiveness. Hospital managers felt the situation had improved since its introduction, particularly in rural hospitals that were within commuting distance of urban areas, where they could use the rural allowance for recruiting staff from the urban hospitals.

However, the big problem with the rural allowance that was identified by almost all the rural nurses who received the allowance was that only professional nurses and not Enrolled Nurses or Nursing Assistants received the allowance. This meant that nurses who received the allowance felt badly for their colleagues and in many cases were faced with colleagues being un-cooperative and saying: "you get the rural allowance, you do the work." Professional nurses stated that it undermined the teamwork that was essential to working in facilities.

"It's not fair that only the professional nurses get rural allowances. Other staff also work in rural areas, they should get also". 
Staff in urban hospitals were also demoralised that they did not receive the rural allowance. They felt that there was also a shortage of staff in urban hospitals and they were also working under harsh conditions. One ward manager reported:

"We wrote a letter to the province saying that we also wanted rural allowance because we have to deal with all the patients referred from rural hospitals"

\section{Ward Manager}

Nurses in urban hospitals, which were often referral hospitals for rural hospitals complained that while the nurses in the rural areas were getting the rural allowance they were not working hard, and referred women to them even when the clinical indications didn't warrant a referral just because they were 'lazy' to nurse the woman themselves.

\section{Award schemes}

A number of managers mentioned various award schemes that had been developed at the national and provincial level to identify and reward good practice among nurses. Some managers felt that these schemes were a wonderful opportunity for nurses to feel appreciated and recognised for their hard work, and stated that nurses in their hospital and clinic receiving the award had made a considerable positive impact on staff morale. Other managers reported that these award schemes were divisive, with accusations of favouritism for those receiving them, and nurses who didn't get awards feeling demoralised. One nursing manager reported that one nurse in her facility received a substantial cash bonus with the award, which caused enormous tension; she had decided that she would not recommend any staff at her hospital to be entered into these schemes again.

\section{"What would you recommend to retain staff?"}

Overwhelmingly, those interviewed recommended more money and more staff. Some managers had unrealistic suggestions, such as doubling pay and doubling the number of staff working at facilities. Other frequently made recommendations included:

- Recognition of post-basic training qualifications in pay scales

- Being paid to do overtime in facilities instead of getting days off in lieu

- Giving the scarce skills allowance to advanced midwives

- Giving all nursing staff the rural allowance, and not just professional nurses

- Rethinking management roles and pay scales

- Allowing nurses to return from overseas at the rank at which they left

- Taking midwifery out of basic training and making it a speciality

- Improving the quality of managers in facilities; and

- Car allowances 


\section{The impact of HIV /AIDS}

While acknowledging the impact of HIV/AIDS, both on their staff and patients, almost all managers felt that the HIV/AIDS epidemic was not a key explanation for the problems that they were facing with their staff. No managers stated that they had a big problem with professional nurses dying of HIV/AIDS, nor did any managers report that sick leave levels and nurses needing to take time off to care for sick family members and attend funerals was a particular problem.

Nurses saw the impacts of the epidemic much more clearly in their patients, and reported that it was distressing to see especially young people get sick and die "in front of your eyes," and not be able to do much to help. Many nurses reported that when people got very sick they gave up coming to the clinic, and just died at home. Nurses working in clinics that did not have testing kits, and so were not able to refer patients to an ARV treatment site, expressed particular frustration. Nurses working at hospitals that were already distributing ARVs reported being happy that this service was being provided in their hospital.

Managers of maternity wards in hospitals mostly reported that it was 'not a problem', as sick patients were usually referred elsewhere, either to the medical ward or to a referral hospital. The large number of HIV-positive patients and the risk of exposure was a concern to nurses, but most managers reported that they believed that infection control measures, and the availability of post exposure prophylaxis, meant that it was not a major issue for their staff. Some reported that young and pregnant nurses appeared to be more concerned about risk of exposure, and would often request to be moved out of the maternity section to reduce the likelihood of exposure.

A common theme was the perception that it was the more junior staff at facilities, and not the professional 'educated' nurses, who were more likely to be HIV positive or to die of AIDS. Some nursing managers admitted that there were strong incentives for professional nurses not to be open about their HIV/ AIDS status, partly because patients would not want to be nursed by someone they knew was HIV positive, and partly because of fear of negative attitudes from colleagues.

"Tell me the honest truth...would you want an HIV positive nurse to deliver your baby? No. And that is why if you are a nurse in maternity and you have this HIV you keep quiet”

\section{Nursing Manager}

"In other hospitals you hear that they are burying a nurse every week. But it is not like that here. I think before they get sick they resign (they)...don't want us to see them getting sick and gossiping about them. And we nurses, we do gossip"

\section{Nursing Manager}

A few managers speculated that some of the professional nurses who had left the facility and cashed in their pensions were in fact HIV positive. Some of the managers reported that if they knew, or even suspected, that a professional nurse was HIV 
positive then they would move her from the maternity section to prevent the risk of her infecting mothers and newborn babies.

\section{Quality of care}

There was reluctance among many staff to admit that the quality of care they provided was poor. Staff wanted to present an image of working hard, treating clients with respect and providing a good service, despite the problems they faced. Many managers suggested that they prioritised maternity services in their facilities, and so other departments suffered more severely from understaffing.

However some staff, particularly hospital managers, did admit that there were serious problems of quality of care in their maternity units. Problems identified included staff not monitoring patients correctly, not doing accurate and timely reporting and taking their frustrations out on patients; all these have been identified as key problems also in the Confidential Enquiry into Maternal Deaths. At the ward and clinic management level, many nurses reported that they just didn't have time to give women the counselling, support and education that they needed.

Some managers argued that their staff were faced with impossible workloads and did the best they could under difficult circumstances. Others argued that the problem was not about numbers of staff, but with the work ethic of nurses working in their maternity wards.

"There are those who understand they are nurses....others they just like to loiter"

\section{Nursing Manager}

A number of hospital and ward managers suggested that many of the workload problems were caused by poor allocation of staff to certain unpopular shifts and not shortages of staff overall. Other managers identified the problem of staff sometimes being faced with a sudden influx of patients and systems not being in place to call in other staff to support them when this happened.

\section{Nursing management}

Problems with both nursing and facility management emerged as prominent themes and were apparent during some of the site visits. These problems can be broadly classified into three categories. First, management in some facilities was unstable and apparently in a state of disarray. In one facility, three different staff members identified themselves as the acting CEO at the facility. At another facility they didn't have a CEO as the previous one had recently been shot in a dispute with a community member and so had "run away" from the facility. In these facilities, the chaos in the hospital management appeared to have affected all levels of the facility.

Second, in some facilities there were extremely high levels of tension between staff and management, with industrial action either taking place, having just taken place, or being threatened. These disputes were about a range of issues. At one facility the CPNs were protesting that they didn't have 'posts' and so had to do more clinic 
duties instead of management duties that were more appropriate to their rank. At another facility, the management was faced with industrial action as CPNs resented having to hold ward management positions. Many managers talked about being frustrated with their inability to make improvements in their facilities due to nurses' attitudes. At the ward and clinic management level, nurse managers talked about frustrations with hospital management. They felt that management personnel were routinely unfair, dictatorial and bad at their job.

"People were crying for promotions during apartheid times.... but when they get them (promotions) they behave just like those white matrons in the those days of apartheid. And our people don't want that and that is when they chase them away"

\section{Sister-in-charge of maternity}

"They give the job to just anybody, usually they are the girlfriend of somebody, it doesn't matter if they don't know anything about management”.

\section{Clinic Manager}

Third, a number of managers reported that they were trying to improve the quality of care, and the quality of management, but were faced with nurses who were not happy with the changes. Changes in management styles that attempted to reward ability and not length of service, as well as changes that were perceived to favour some staff over others, appeared to be the hardest to implement. For example one nurse manager reported that she had tried to send her best nurses on training, because she had confidence that they would understand the training and be able to feed it back to the other nurses in the ward. This led to such problems that she now sends all nurses for training on rotation, despite the fact that, in some cases, information feedback was poor:

"To change is very difficult. I never believed it was that difficult but now I see".

Nursing manager

"You try and bring innovations and they say 'who are you to change us...don't come here and order us...you meet such resistance you just give up"

Nursing manager. 


\section{CONCLUSIONS AND RECOMMENDATIONS}

\section{Nursing Staff Dynamics In Kwa-Zulu Natal, Mpumalanga and Limpopo.}

This study clearly shows that nursing staff in South Africa are mobile, although their movements are not simply from rural to urban, and from urban to overseas as has been suggested in much of the literature on nursing migration (Marchal \& Kegels, 2003, Lehmann \& Sanders, 2004). Although many nurses are moving from the public health system to overseas, some nurses are also moving between facilities, between provinces, from urban to rural and rural to urban, from the public sector to the private sector and overseas, as well as now back from the private sector and overseas to the public sector. These different directions are caused by different factors, both financial and non-financial. Although it is complicated to map and quantify these movements, more work needs to be done to better understand the reasons for the movements and how to deal with them. For example, obstacles to nurses returning to the public sector, such as restriction on what rank they can be re-employed at, need to be clearly identified and reviewed.

Increased deployment of advanced midwives has been identified as a key strategy to improve the quality of care in South African maternity services, but it is of concern that, in the study facilities, there was a net outflow of advanced midwives in the first half of 2004. Clearly policies need to be developed that will facilitate retention of this cadre of nursing staff, such as: recognition of post-basic training in pay structures, or extending the scarce skills allowance to include advanced midwives. Attention also needs to be paid to ensuring that promotion is available to advanced midwives in such a way that their clinical expertise is fully utilised. Also to be considered is that previous research has found that advanced midwives sometimes struggle to make changes in the quality of care provided in maternity units if they are not in a position of power (Penn-Kekana, 2004). The lack of advanced midwives in clinics is worrying because many clinic managers reported that they were being pressured to start doing deliveries at their clinics. The National Guidelines on Maternity Care suggest that at least one advanced midwife should be working at every facility which routinely handles deliveries.

In terms of vacancy rates the levels found in this study were not as disastrously high as have been suggested elsewhere particularly for Mpumalanga province. (Padarath et al, 2004). Still, a 30\% vacancy rate is still high, and must seriously impact on the quality of care provided at that facility. Officials in the provincial government in Mpumalanga reported that there had been a drive to recruit staff, and the unfreezing of posts in the province in the last year. At the hospital management level in some hospitals in Mpumalanga this was acknowledged, but staff at the ward level did not report a significant improvement in staffing levels. In fact they reported that things were getting worse. At many facilities at both the ward and hospital management level informants were unclear about what their staffing establishment was, how staffing establishments were set, who set them and why they had been set at the level that they had been set. Connected to the issue of vacancy rates is the issue of too many nurses at the Chief Professional Nurse rank, which was reported at almost 
all facilities. As discussed in the results section this caused a large amount of unrest and bad feeling amongst staff. CPNs were not happy about their roles and responsibilities, and nurses in lower ranks felt that they had no chance of promotion to a higher grade as the hospital already had its full allocation of CPNs. The motivational section of this study found that lack of promotion opportunities was a factor in nurses intending to leave facilities. Unfortunately these results are not analysable by category of professional nurse.

Workloads varied considerably between facilities. Staff in some facilities appeared to be dealing with extremely high workloads, while at others the workload did not appear to be so challenging. These findings may partly reflect methodological challenges but also suggest that the statement that almost all nursing managers and many staff made that they are overworked needs to be integrated and not always taken at face value.

Staffing levels also need to be sensitive to fluctuations that occur in workload between shifts, from day to day and from month to month. Nurses' perceptions that they are overworked often appear to be disproportionately shaped by their recollection of the one shift where they had to deliver six babies, and not by the many shifts where the workload was relatively light. Suggestions were made at the feedback workshops that a maximum number of deliveries that one nurse can manage should be set, and when this number is exceeded on any particular shift another nurse should be called in to assist. This does happen on an informal basis in many facilities, but it was suggested that this should be formalised by setting up an on-call system. Although established within the medical profession there is not a tradition of on-call system in nursing and this would be complicated to establish. In some of the Limpopo clinics some form of on-call system existed and this was causing high levels of discontent around pay levels, and allocation of who was on call.

During site visits it was found that in some hospitals, particularly on night shifts, professional nurses allocated to maternity sections often had support responsibilities in other wards which were staffed by less qualified nurses. In one hospital, for example, one professional nurse on night duty was in charge of both the maternity and the casualty sections. As it was a small hospital, most nights this was not a problem, but nurses could recall nights when they had to move between dealing with a gunshot wound and with a woman in active labour. Although management of health care is always going to involve fluctuations in workload, systems should be in place to avoid and ameliorate these situations, as they appear to be having a longterm and negative impact on nursing morale.

Discussions during the feedback workshops also noted that development of a workload-based staffing norm will always be problematic and may not be that desirable. There is debate about the advantages and disadvantages of using workload as opposed to population-based methods to set staffing levels, or whether a formula should be used to combine the two approaches. Even if a workload approach is taken, a complex formula needs to be developed around headcounts, workloads, case mix and various sets of norms, as well as problems with recognising 
the different circumstances that facilities face. For example, a hospital where a nurse has to spend two hours on the phone trying to locate a doctor or to ensure that the ambulance arrives will have different staffing needs than a facility where the doctor is easily accessible and an ambulance is based at the hospital. Finally the issue of staff morale and the quality of ward or clinic management also needs to be factored into discussions about workload.

\section{Exploring Factors Associated with Nursing Staff Dynamics}

While acknowledging that many nurses have left public facilities, there is a sizable majority of nursing staff who do stay in the public sector, as illustrated by the fact that the average length of stay of nurses was nine years in Mpumalanga and KwaZulu-Natal and nearly six years in Limpopo. Ward and clinic level managers also appear to be relatively stable.

It is disturbing that the nurses remaining in the public sector are often demoralised, burnt-out, and have low levels of organisational commitment. Nurses' perceptions and discourses reflected that they felt underpaid, overworked, unappreciated and not supported by management, at the facility, provincial and national levels. Many wished that they had not chosen nursing as a profession, and almost all would not recommend to their children to become nurses.

Both the study results, and the discussion held at the feedback workshops, suggest that management and interpersonal relationships at facility level are an important point at which to intervene for improving nurses' morale and for retaining them at facilities. The results of the discrete choice experiment showed that the quality of management significantly influenced nurses' hypothetical choices about preferred facilities, and the multivariate analysis found that poor relationships with coworkers was associated with nurses intention to leave. The fact that many managers themselves are demoralised and thinking about leaving makes interventions at this level imperative and more of a challenge.

This low level of morale among nurses and facility-level management does not create an environment conducive for policy interventions. This can be seen clearly in nurses' responses to a number of policies that have attempted to improve the quality of care and retain staff in facilities, and so policy makers need to consider this environment when they are formulating policy interventions. More attention needs to be paid to the impact of reforms and policies on relationships between staff, and between staff and management. When introducing incentive schemes such as the scarce skills allowances and the rural allowance, thought needs to be given to the impact on the morale of staff that are not going to get the allowance. Double demotivation occurs in cases where staff that do get the allowance feel bad because their colleagues don't, and/or have to deal with these colleagues not cooperating because of resentment.

There appears to be a strong belief among South African nurses, rightly or wrongly, that all staff need to be treated equally, and that length of service should be the key criterion for how staff are evaluated and promoted. High levels of suspicion that 
managers often make decisions based on nepotism and self-interest accompany this. Introducing new ways of managing and rewarding staff may be desirable, but this is an extremely challenging process and cannot be achieved overnight, or without increased support to facility managers.

The need to monitor the impact of reforms on nursing dynamics and morale was emphasised at the feedback workshops. It was suggested that the tools developed in this project could be adapted for use by province managers for measuring staff morale, so that problems can be anticipated and dealt with.

\section{The Impact of HIVIAIDS}

This study did not find alarmingly high levels of professional nurses getting sick and dying of HIV/AIDS. Neither did the high numbers of patients with HIV appear to be having a negative impact on the morale of nursing staff. This is not to say that nurses are not getting sick and dying, or that the impact of caring for patients with HIV/AIDS is not impacting on nurses, but that these factors should not be seen as the driving force behind problems with nursing dynamics in South Africa. Instead, HIV/AIDS should be seen as one of many factors that contribute to nursing staff moving within and out of the public sector. It also needs to be acknowledged that, due to the stigma often associated with HIV and coupled with the perception that professional nurses are 'knowledgeable' about HIV and part of a 'caring profession', more complex perceptions of nurses towards HIV/AIDS and of living with HIV are difficult to determine in a study such as this.

\section{Future Research and Utilisation of the Study}

Analysis of trends in nursing turnover in the last five years should be attempted using the Vulindlela database (the human resource database used by public service in South Africa), despite problems with the quality of data in the database (Doherty \& Joffe, 2003). Although originally intended to be part of this study, it was not possible for the investigators to access and analyse these data within the timeframe of this study.

The $\mathrm{NDOH}$ is planning a national situational analysis of maternal and neonatal services throughout South Africa, and the tools developed for this study could be included by this situational analysis. The national situational analysis will sample a larger number of facilities in all nine provinces in South Africa and therefore will provide an opportunity to determine whether the findings are generalisable to the whole country. It will also provide a large enough sample size to test statistically the relationship between staff morale and clinical outcomes.

The NDOH is in the final stages of developing a new human resource strategy. More attention is also being paid to issues of human resource management and staff retention at a provincial and district level. Researchers need to work more closely with policy implementers to measure the impact of this initiative. The Nursing Services Directorate in Limpopo province is also exploring the issue of using some of the tools as a way of monitoring the impact of interventions to improve the quality 
of nursing in the province. Some elements of the self-administered questionnaire have also been adapted to monitor staff morale in Gauteng. 


\section{APPENDICES}

\section{Appendix 1a: Conceptual Framework for Staff Motivation}

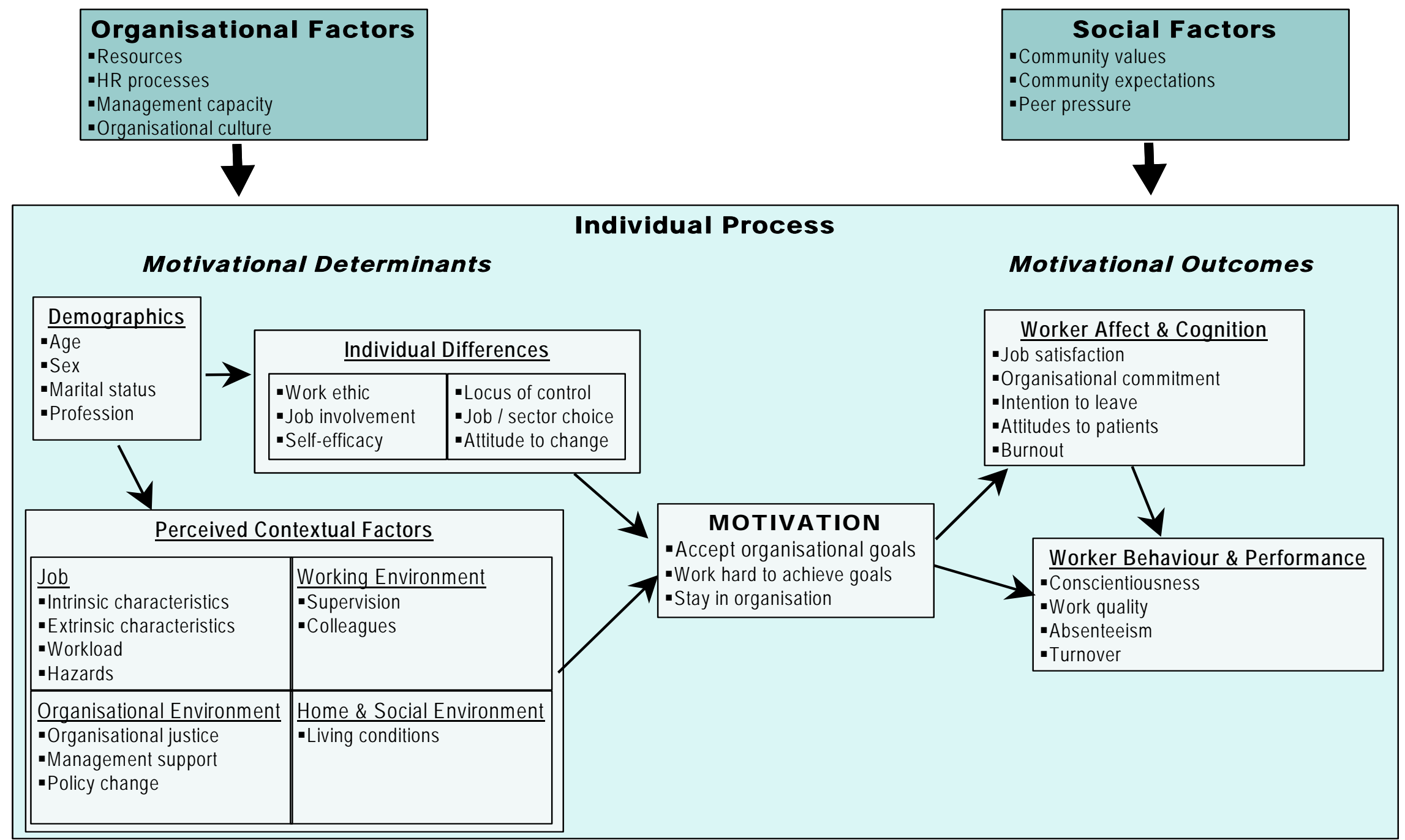

Nursing Staff Dynamics and Maternal Health Services in the Context of HIV/AID 


\section{Appendix 1b: Questions used according to the conceptual framework}

\begin{tabular}{|c|c|c|c|}
\hline & Area & Domain & Questions \\
\hline \multirow{16}{*}{$\begin{array}{l}\text { Motivational } \\
\text { Outcomes }\end{array}$} & \multirow{16}{*}{$\begin{array}{l}\text { Worker affect \& } \\
\text { cognition }\end{array}$} & \multirow[t]{2}{*}{ Motivation } & These days, I don't feel motivated to work as hard as I could \\
\hline & & & I only do this job so that I get paid at the end of the month \\
\hline & & Job Satisfaction & Overall, I am very satisfied with my job \\
\hline & & \multirow{4}{*}{$\begin{array}{l}\text { Organisational } \\
\text { Commitment }\end{array}$} & I am proud to be working for this hospital/clinic \\
\hline & & & I find that my values and this hospital/clinic's values are very similar \\
\hline & & & I am glad I work for this facility rather than other facilities in the province \\
\hline & & & I feel very little commitment to this hospital/clinic \\
\hline & & \multirow[t]{3}{*}{ Intention to Leave } & I can see myself working overseas in the future \\
\hline & & & I prefer t to work in the public sector \\
\hline & & & I intend to leave this hospital \\
\hline & & \multirow{3}{*}{$\begin{array}{l}\text { Attitudes to } \\
\text { Patients }\end{array}$} & In this hospital we always treat patients with respect \\
\hline & & & I feel that I don't care for patients like I used to \\
\hline & & & A nurse who hits a patient should be dismissed \\
\hline & & Attitudes to HIV & Caring for patients with HIVIAIDS is very demoralising \\
\hline & & \multirow{2}{*}{ Burnout } & I feel emotionally drained at the end of every day \\
\hline & & & When I get up in the morning I dread having to face another day at work \\
\hline \multirow{36}{*}{$\begin{array}{l}\text { Motivational } \\
\text { Determinants }\end{array}$} & \multirow{12}{*}{$\begin{array}{l}\text { Individual } \\
\text { Characteristics }\end{array}$} & \multirow{3}{*}{$\begin{array}{l}\text { Work Ethic / Job } \\
\text { Involvement }\end{array}$} & The major satisfaction in my life comes from my work \\
\hline & & & Doing my job well makes me feel worthwhile \\
\hline & & & I work hard because of my religious beliefs \\
\hline & & \multirow{2}{*}{\begin{tabular}{|l|} 
Self efficacy / \\
Locus of control \\
\end{tabular}} & I feel that I am not in control of things which affect my work \\
\hline & & & I am confident about my ability to do my job \\
\hline & & \multirow{4}{*}{$\begin{array}{l}\text { Vocation / Job } \\
\text { Choice }\end{array}$} & I would recommend to my children that they become nurses \\
\hline & & & I always wanted to be a nurse \\
\hline & & & I am proud to tell others that I am a nurse \\
\hline & & & I wish that I had chosen a different occupation from nursing \\
\hline & & \multirow[t]{3}{*}{ Attitude to Change } & Changes in the health sector have opened up new career opportunities for me \\
\hline & & & I cope well with change \\
\hline & & & There have been too many changes in this hospital in the past few years \\
\hline & \multirow{24}{*}{\begin{tabular}{|l|} 
Perceived \\
Contextual \\
Factors
\end{tabular}} & \multirow[t]{2}{*}{ Workload } & There are enough nursing staff to do the work in this unit \\
\hline & & & The amount of work I have to do is too demanding \\
\hline & & \multirow{3}{*}{$\begin{array}{l}\text { Extrinsic Job } \\
\text { Characteristics }\end{array}$} & With this job I have to worry about how to support myself and my family \\
\hline & & & There are sufficient opportunities for promotion in my facility \\
\hline & & & My job offers adequate pay compared with similar jobs \\
\hline & & \multirow{4}{*}{$\begin{array}{l}\text { Organisational } \\
\text { Citizenship }\end{array}$} & My co-workers are jealous of my expertise and not willing to learn from me \\
\hline & & & The doctors and nurses work together well is this unit \\
\hline & & & If there is an emergency you can rely on the doctors in this hospital \\
\hline & & & There is too much gossip in this hospital \\
\hline & & \multirow{2}{*}{$\begin{array}{l}\text { Supervision and } \\
\text { Support }\end{array}$} & I do not get adequate support and supervision from my supervisor \\
\hline & & & I am able to talk to my supervisor about a personal problem affecting my work \\
\hline & & \multirow{4}{*}{$\begin{array}{l}\text { Management } \\
\text { Support }\end{array}$} & If you make a mistake the management at this facility will support you \\
\hline & & & $\begin{array}{l}\text { Suggestions made by nurses on how to improve their work are usually ignored by } \\
\text { hospital management }\end{array}$ \\
\hline & & & Hospital management communicates well with nurses in this hospital \\
\hline & & & I like how this hospital/clinic treats its employees \\
\hline & & \multirow{2}{*}{$\begin{array}{l}\text { Organisational } \\
\text { Justice }\end{array}$} & The nurses who are the best at their job are the ones who get promoted \\
\hline & & & $\begin{array}{l}\text { When it comes to getting a promotion, who you know is more important than what you } \\
\text { know }\end{array}$ \\
\hline & & \multirow[t]{2}{*}{$\begin{array}{l}\text { Stress/Work } \\
\text { Hazards }\end{array}$} & $\begin{array}{l}\text { The stress of working in the labour ward has made me think about transferring to } \\
\text { another ward }\end{array}$ \\
\hline & & & I am worried about being assaulted by patients or their relatives at work \\
\hline & & HIVIAIDS & I am worried about contracting HIVIAIDS outside of work \\
\hline & & Hazards & The risk of HIV has made me think about leaving my job \\
\hline & & & A lot of nurses are dying of HIVIAIDS \\
\hline & & Policy Environm & $\begin{array}{l}\text { The Department of Health does not adequately consider the effect of their decisions on } \\
\text { staff when developing new policies }\end{array}$ \\
\hline & & & We are well informed about policy changes affecting our work \\
\hline
\end{tabular}




\section{Appendix 2: Figures showing Selected Determinants of Motivation among Professional Nurses.}

Figure 8 Selected determinants of motivation among professional nurses

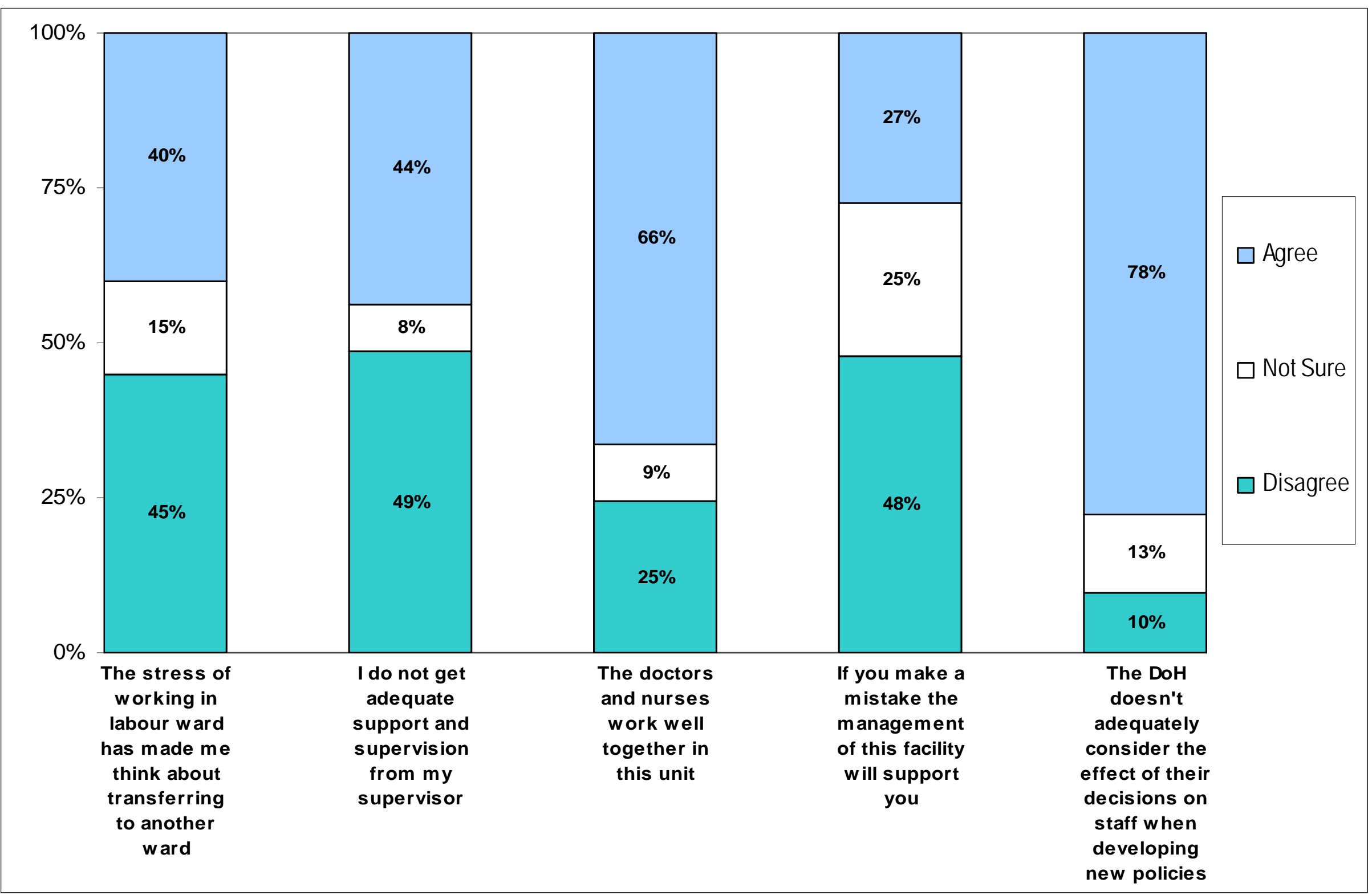


Figure 9 HIVIAIDS-related determinants of motivation amongst professional nurses

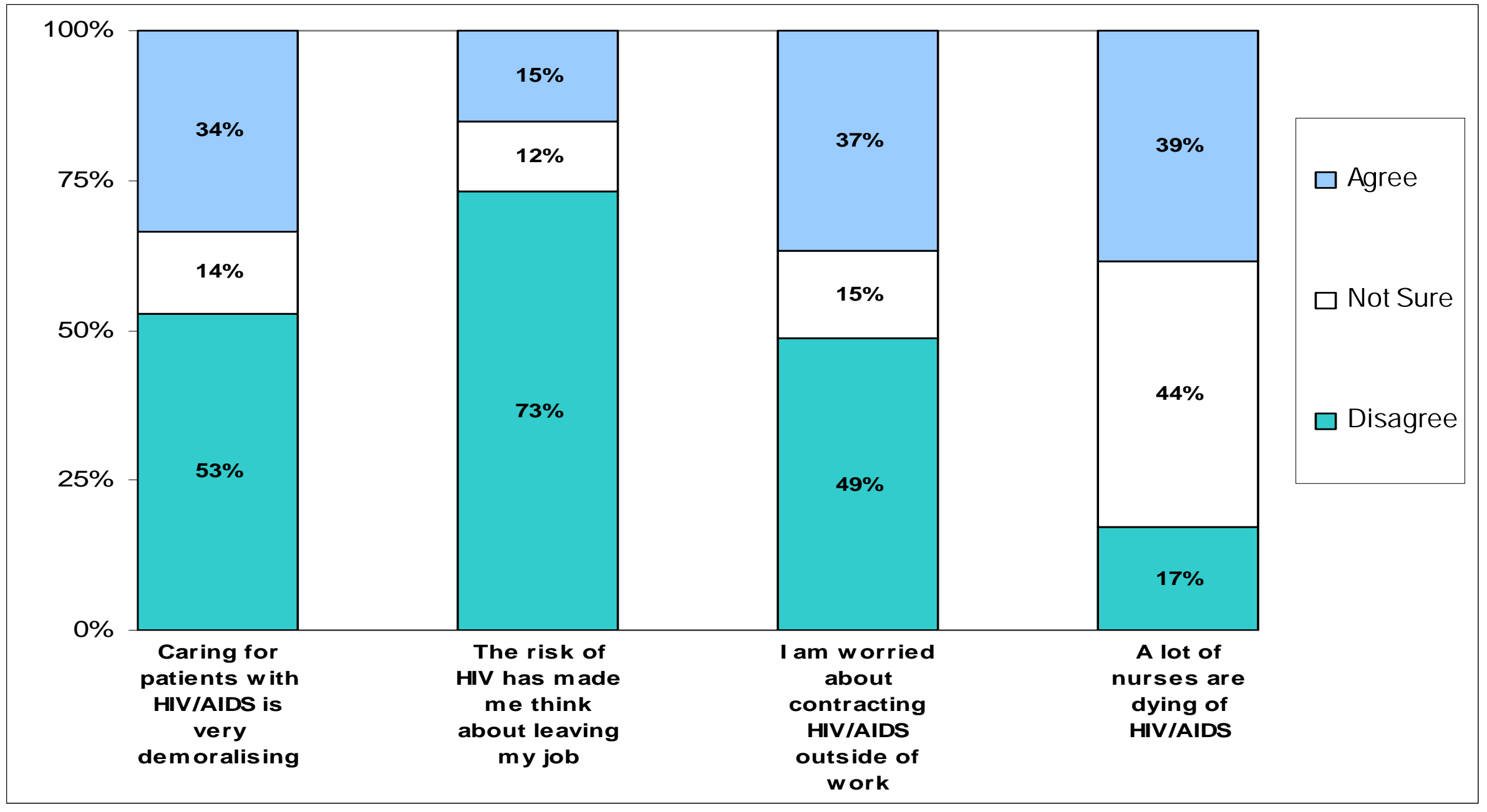


Appendix 3: Factor Analysis of Motivational Questions Included in the Self-Administered Questionnaires

\begin{tabular}{|c|c|c|c|}
\hline Area & Original Constructs & Factor Analysis & $\begin{array}{c}\% \\
\text { Variance }\end{array}$ \\
\hline $\begin{array}{l}\text { Motivational } \\
\text { Outcomes }\end{array}$ & $\begin{array}{l}\text { 1. Motivation } \\
\text { 2. Job Satisfaction } \\
\text { 3. Organizational Commitment } \\
\text { 4. Intention to Leave } \\
\text { 5. Attitudes to Patients } \\
\text { 6. Attitudes to HIV } \\
\text { 7. Burnout }\end{array}$ & $\begin{array}{l}\text { 1. Burnout / Demotivation } \\
\text { 2. Intention to Leave } \\
\text { 3. Organizational Commitment } \\
\text { 4. Ethical Values } \\
\text { 5. Attitudes to Patients }\end{array}$ & $\begin{array}{r}39.3 \\
10.0 \\
8.5 \\
7.9 \\
6.3 \\
62.0 \%\end{array}$ \\
\hline $\begin{array}{l}\text { Motivational } \\
\text { Determinants }\end{array}$ & $\begin{array}{l}\text { 1. Work Ethic / Job Involvement } \\
\text { 2. Self efficacy / Locus of control } \\
\text { 3. Vocation / Job Choice } \\
\text { 4. Attitude to Change } \\
\text { 5. Intrinsic Job Characteristics } \\
\text { 6. Workload } \\
\text { 7. Extrinsic Job Characteristics } \\
\text { 8. Organizational Citizenship } \\
\text { 9. Supervision and Support } \\
\text { 10. Management Support } \\
\text { 11. Organizational Justice } \\
\text { 12. Stress/Work Hazards } \\
\text { 13. HIVIAIDS Hazards } \\
\text { 14. Policy Environment }\end{array}$ & $\begin{array}{l}\text { 1. Facility Mx }+ \text { Supervisor Relationships } \\
\text { 2. Vocation } \\
\text { 3. Stress/Work Hazards } \\
\text { 4. Extrinsic Job Characteristics } \\
\text { 5. Co-Worker Relationships } \\
\text { 6. Self efficacy } \\
\text { 7. Nurse-Doctor Relationships } \\
\text { 8. Workload } \\
\text { 9. Religious Beliefs } \\
\text { 10. Fear of Assault } \\
\text { 11. Coping with Change } \\
\text { 12. Fear of HIVIAIDS } \\
\text { 13. Concern about Supporting Family }\end{array}$ & $\begin{array}{r}19.1 \\
7.4 \\
6.8 \\
6.4 \\
5.3 \\
4.9 \\
4.6 \\
3.9 \\
3.6 \\
3.3 \\
3.2 \\
2.9 \\
2.8 \\
74.2 \%\end{array}$ \\
\hline
\end{tabular}




\section{REFERENCES}

Bennet S, Franco L, Kanfer R, Stubblebine R (2001). The Development of Tools to Measure the Determinants and Consequences of Health Care Worker Motivation in Developing Countries. Partnerships for Health Reform. Abt Associates Inc. Maryland.

Blaauw D, Penn-Kekana L. (2003). Socio-Economic Inequalities and Maternal Health in South Africa. Presentation to the $22^{\text {nd }}$ Conference on Priorities in Perinatal Care in Southern Africa.

Buchan J, Sochalski J (2004). The migration of nurses: trends and policies. Bulletin of the World Health Organisation. August 2004, 82 (8).

Chege J, Mosery N, Ndube-Nzumalo M, Kunene B, Beksinska M, Dalton J, Snyman E, Sturm W, Moodley P, (2004). Feasibility and Effectiveness of a Comprehensive Integrated Package of Antenatal Care Services in Rural Public Clinics In South Africa. Frontiers in Reproductive Health. Population Council.

Doherty J, Joffe A (2003). Trends in Skilled Health Personnel 1996-2002. Mimeo, 2003.

Fonn S, Xaba M, Tint K, Conco D, Varkey S (1998). Maternal health services in South Africa. South African Medical Journal. Vol 88. No 6. June.

Hongoro C, McPake B (2004). How to bridge the gap in human resources for health. Lancet. 364. 1451-56.

Jewkes R, Abrahams N, Mvo Z (1998). Why do nurses abuse patients? Reflections from South African Obstetric Services.

Social Science and Medicine. Vol 47. No 11.1781-1795.

Lehmann U, Sanders D (2004). Human Resources for Health in South Africa. JLI National Consultation $3^{\text {rd }}-4^{\text {th }}$ of September 2004. Cape Town South Africa. Background \& Overview Paper.

Marchal B, Kegels G (2003). Health workforce imbalances in times of globalization: brain drain or professional mobility? International Journal of Health Planning and Management. 18: S89 - S101.

McCoy D et al (2005). Expanding Access To Antiretroviral Therapy in Sub-Saharan Africa: Avoiding the Pitfalls and Dangers, Capitalizing on the Opportunities. American Journal of Public Health. Jan 2005. Vold 95 No.1.

Mensah K, Mackintosh M, Henry L (2005). The 'Skills Drain' of Health Professionals from the Developing World: a Framework for Policy Formulation. Medact.

London.

National Department of Health (2001). Final Draft Report. South African Demographic and Health Survey 1998.Department of Health. Pretoria. 
National Department of Health (2002). Guidelines for Maternity Care in South Africa. A manual for clinics, community health centres and district hospitals. Department of Health. Pretoria.

National Department of Health (2003). Saving Mothers 1999-2001. Department of Health.

Padarath A, Ntuli A, Berthiaume L (2004). Human Resources. In Ijumba P et al. South African Health Review 2003/4. Chpt 22. Durban: Health Systems Trust.

Penn-Kekana L \& Blaauw D (2002). A Rapid Appraisal of Maternal Health Services in South Africa: A Health System's Approach. Centre for Health Policy.

Pick W, Nevhutalu K, Cornwall J, Masuka M (2001). Human Resources for Health. A National Strategy. National Department of Health. Pretoria.

Price JL (1997) Handbook of organizational measurement. International Journal of Manpower, 18 (4/5/6), 305-558.

Ryan, M \& Farrar S (2000) Using conjoint analysis to elicit preferences for health care. BMJ, 320, 1530-1533.

Shisana O et al. (2003). The Impact of HIV / AIDS on the Health Sector. A National Survey of Health Personnel, Ambulatory and Hospitalised Patients and Health Facilities, 2002. National Department of Health. Pretoria.

Smith H, Brown H (2001). Preliminary findings from pilot implementation. Priorities in Perinatal Care Conference. 2001.

Stilwell B, Dialo K, Zurn P, Vujicic M, Adams O, Dal Poz M (2004). Migration of health care workers from developing countries: strategic approaches to its management. Bulletin of the World Health Organisation. August 2004, 82 (8).

Tawfik L \& Kinoti S (2003). The Impact of HIV/AIDS on Health Systems and the Health Workforce in Sub-Saharan Africa. USAID.

Travis P, Bennett S, Haines A, Pang T, Bhutta Z, Hyder A, Pielemeier N, Mills A, Evans $T$ (2004). Overcoming health-system constraints to achieve Millennium Development Goals. Lancet. Vol 364. September 4.

UNICEF/WHO/UNFPA (1997). Guidelines for monitoring the availability and use of obstetric services. www.who.int/reproductive-health/publications/unicef/ 
Page: 23

[DB1]Need to work on the referencing of the appendices 